\title{
Experimental Studies on the Behaviors of New Energy-Saving Concrete Self-Insulating Load-Bearing Block Wall under Low-Cycle Cyclic Loading
}

\author{
Bashir H. Osman ${ }^{1,2}$ and Zhongfan Chen $\mathbb{D}^{2}$ \\ ${ }^{1}$ Civil Engineering Department, College of Engineering, University of Sinnar, Sinnar, Sudan \\ ${ }^{2}$ Key Laboratory of RC\&PC Structures of Ministry of Education, Southeast University, Nanjing 210096, China
}

Correspondence should be addressed to Zhongfan Chen; 101003944@seu.edu.cn

Received 26 December 2017; Revised 29 March 2018; Accepted 17 July 2018; Published 4 October 2018

Academic Editor: Patrice Berthod

Copyright (c) 2018 Bashir H. Osman and Zhongfan Chen. This is an open access article distributed under the Creative Commons Attribution License, which permits unrestricted use, distribution, and reproduction in any medium, provided the original work is properly cited.

\begin{abstract}
Masonry walls are usually designed to resist the effect of lateral and gravity loads resulting from wind or earthquake excitations. This research aimed at investigating the inelastic behavior of a new energy-saving concrete self-insulating load-bearing block wall (ECSLBW) under in-plane cyclic loading. To provide stronger bond between the concrete block units better than the ordinary concrete masonry units, a new masonry system of concrete blocks with special configurations was made. In this experiment, three new self-insulated block wall specimens were designed, manufactured, and tested. Furthermore, selfsupporting structural column-ring beam structure system was used to observe the failure mode of the walls. Moreover, the mechanical properties and seismic indexes of the walls under lateral low-cyclic loading were analyzed, including hysteretic and skeleton curves, stiffness degradation, ductility, and energy losses. The results showed that the new energy-saving block wall can meet the seismic shear calculation under 8-degree rare earthquake and meet the antiseismic fortification target in 8-degree area. Furthermore, self-contained system can greatly improve the seismic shear capacity of the wall. Finally, the seismic shear capacity of the concrete column block masonry was calculated, and the technical application method of block masonry structure was recommended.
\end{abstract}

\section{Introduction}

Masonry is used worldwide for many centuries as a common construction material. However, the weakness of unreinforced masonry systems is mentioned during earthquakes. Accordingly, reinforcement was used in masonry shear walls to resist lateral stresses generated in high regions of seismic action, which results in overturning moments due to simultaneous gravity and lateral loads during seismic excitation.

Masonry shear walls (MSWs) are usually designed to resist the effect of lateral load and gravity load resulting from wind loading or earthquake excitation. The design criteria depend on many factors, including the magnitude of axial loading, amount of flexural and shear reinforcement, wall aspect ratio $(H / L)$, and the mechanical properties of masonry [1-4]. Furthermore, many studies conducted by several researchers [5-13] on shear behavior provide adequate information to ensure that shear failure can be avoided.

Recently, most of the developed countries apply the energy conservation concept in building technology to provide alternative building materials which have positive contributions to the relative environment. Thus, a newly developed type of concrete masonry unit with self-insulating structures with low to medium heights in seismic area zones with severe ambient conditions is used for residential buildings [14]. In the last decade, the developed system of a new type of clay masonry was used in the construction of single-story buildings which has good thermal isolations, with the capability to be used in earthquake zones [14-18]. Accordingly, there is a vital need for a comprehensive study to evaluate the parameters that affect the behavior of the new 
energy-saving concrete self-insulating load-bearing block wall (ECSLBW) under earthquake excitation.

In this paper, the behavior of three full-scale masonry shear walls which were built from a new type of selfinsulating concrete masonry unit under in-plane loading has been evaluated and tested. Furthermore, the relationship between the key design parameters was defined to facilitate a better understanding of the inelastic behavior of a new energy-saving concrete self-insulating load-bearing block wall (ECSLBW) under seismic loading.

\section{Research Focus}

This study aimed at investigating the mechanical behavior of a new type of self-insulating concrete masonry unit. Before testing of large-scale specimens of masonry wall, the mechanical and thermal behaviors of the developed new type concrete block were studied as described below. Designing a new type of self-insulation and load-bearing block for rural houses in different regions (hot summer and cold winter), and a series of experimental and theoretical studies on the thermal performance, and basic mechanical properties and seismic performance of the new type block wall were carried out. The design method of mix proportion of the recycled concrete block (RCB) and the best replacement ratio of recycled aggregate were studied. The masonry compressive strength and the shear strength tests of energy-saving concrete self-insulation block (ECSB) were carried out, and the basic mechanical properties of ECSB masonry were obtained. Furthermore, numerical models by using ANSYS software were developed to predict the behavior of grouted specimens using simplified micromodeling technique. Different sizes of concrete blocks were used, and the block with $390 \mathrm{~mm}$ length and $280 \mathrm{~mm}$ width showed better compressive, shear, and thermal properties (Figure 1(a)). Finally, a new type of ECSB only with $280 \mathrm{~mm}$ thickness to meet the energy-saving requirements of the cold region was developed (Figure 1(b)). The special configuration of ECSB has advantages in both structural and thermal properties. The structural advantage is providing stronger bonds than the ordinary concrete masonry units by facilitating the grout between the units. On the contrary, the thermal advantage is reducing the thermal bridges by using continuous insulation materials.

According to advanced mechanical and thermal properties of selected shape of ECSB, the large-scale walls of ECSB were fabricated and tested as detailed in the sections below.

\section{Test Specimens Designation and Details}

After the optimized ECSB block was proposed, three largescale new energy-saving concrete self-insulating loadbearing block walls were constructed and tested under inplane cyclic loading as detailed in Table 1.

To avoid the scale effect on the shear capacity of the new self-insulation block wall, the large-scale model was used in this study. Combined with the comprehensive situation of rural areas in China, the vertical compressive stress is
0.2 $\mathrm{MPa}$, which is equivalent to the vertical load of the bottom wall of the three-story building. The design considers whether the structure of the column is with or without holes and other factors, and the specific type of test is illustrated in Table 1 and Figure 2.

3.1. Specimen Production and Material Properties. The average values of the compressive strength for the materials and reinforcements used in this study are detailed in Table 2:

The average compressive strength of the concrete block grade MU5 is $5.9 \mathrm{MPa}$, and the strength of the mixed mortar grade $\mathrm{Mb} 10$ is $11.0 \mathrm{MPa}$. Reinforcement details are as in Table 2. The dimensions of the test specimens and structural column and ring beam are shown in Figure 3, while the reinforcement of the main beam $(400 \mathrm{~mm} \times 600 \mathrm{~mm})$, structural column $(200 \mathrm{~mm} \times 200 \mathrm{~mm})$, and ring beam $(200 \mathrm{~mm} \times 260 \mathrm{~mm})$ is shown in Figure 4 .

\subsection{Test Equipment and Loading System}

3.2.1. Test Setup and Instrumentation. This test was carried out at the structural laboratory of Southeast University, and the test device was designed concerning the code for the seismic test method of buildings. The test loading device is shown in Figure 5.

Figure 5 shows the test setup with the wall bottom (foundation) beam which was anchored to the floor using $32 \mathrm{~mm}$ diameter threaded rods. A hydraulic actuator is mounted horizontally and connected to a steel plate fixed at a concrete loading beam to provide lateral shear force. Transverse rollers that provide stability, two on each side of the wall, were connected to the strong floor, and separate steel frames were anchored. The transverse rollers were adjusted until they were just free from contact with the wall; accordingly, lateral stability is provided.

The vertical load is loaded with four points, and the two jacks act on the top beam through the distribution beam. To ensure that the vertical load is stable during the test process, the loading is controlled by the electrohydraulic servo loading device. The horizontal low-cyclic loading is applied using the MTS 243.70 actuator.

3.3. Loading System. All walls were subjected to $0.2 \mathrm{MPa}$ and $172.48 \mathrm{kN}$ as vertical compressive strength and vertical load, respectively. Before applying the horizontal load, the vertical load was applied to predetermine the value in two stages through the jack. At the same time, the verticality of the specimen was checked, and the load was applied by 5 minutes interval. The vertical load was kept constant throughout the test process. The lateral load of each stage is applied once (i.e., loading and unloading in the positive and negative directions), and the load level is $50 \mathrm{kN}$.

Three stages were considered for loading the walls as follows. First stage, the axial load was applied till reaching the specified value, and then, it was kept constant till the end of the test. Second stage, the test was controlled by force till yield point of flexural reinforcement. In the third stage, the 

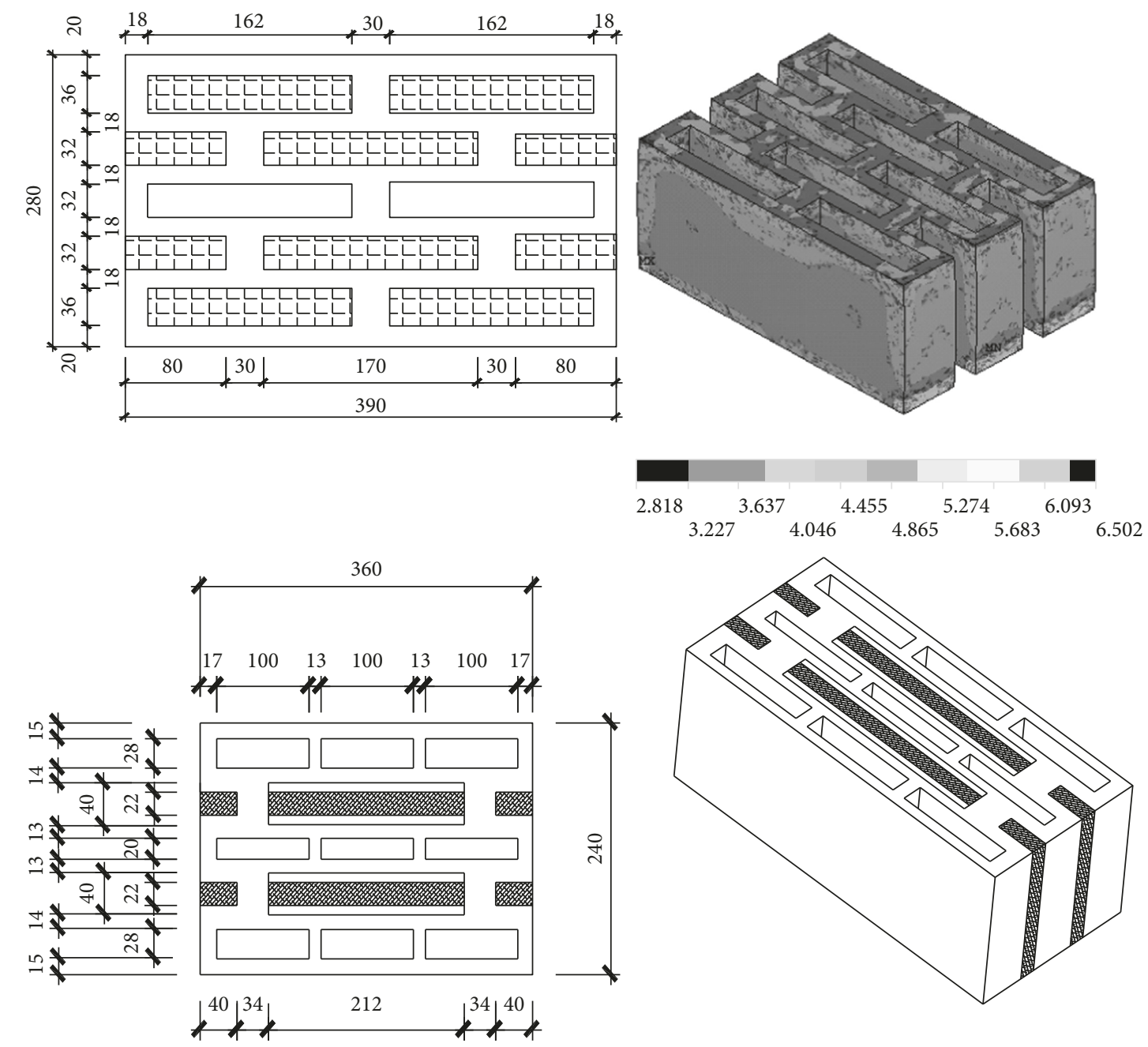

(a)

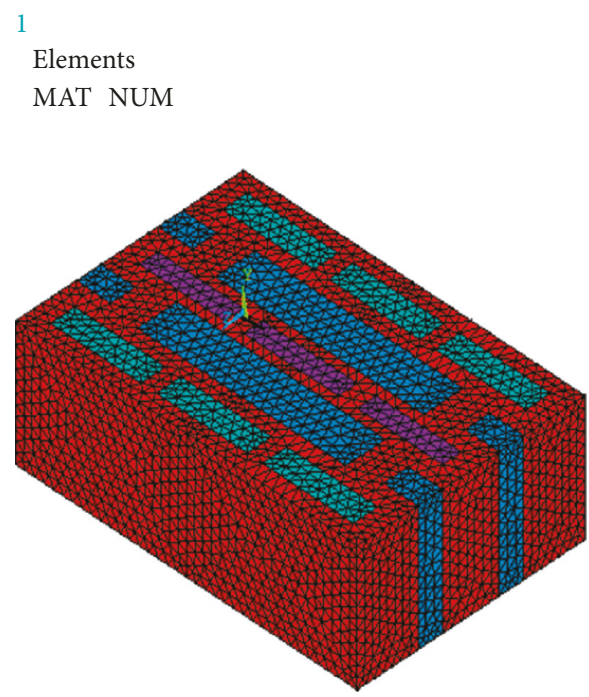

1

Nodal solution

STEP $=1$

SUB $=1$

TIME $=1$

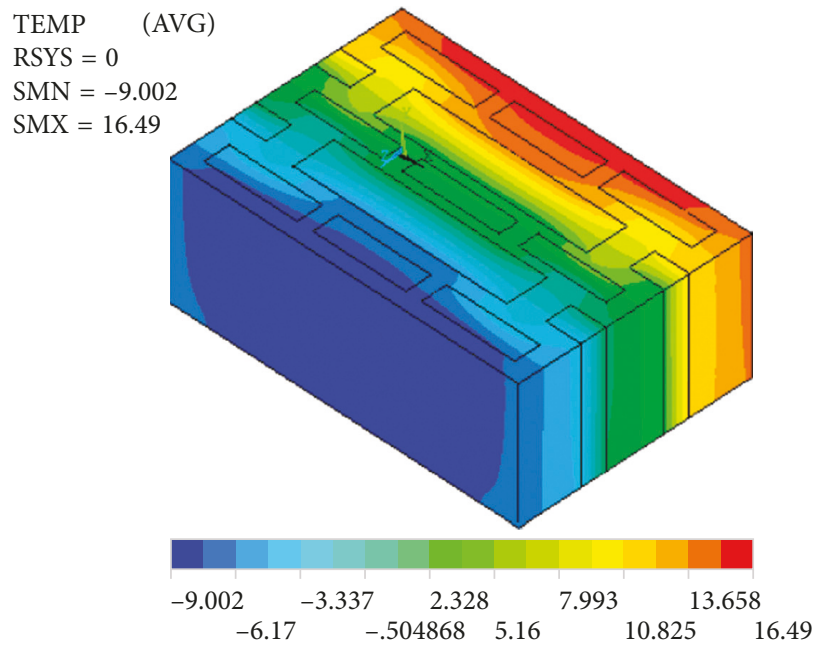

qikuai

qikuai

(b)

FIGURE 1: Self-insulating concrete masonry unit configurations: (a) samples of tested ECSB blocks and (b) thermal properties of proposed ECSB using ANSYS. 
TABle 1: Wall specimens' details.

\begin{tabular}{lccccc}
\hline Wall ID & Specimen size $(\mathrm{mm})$ & Vertical compressive stress $(\mathrm{MPa})$ & Vertical load $(\mathrm{kN})$ & Opening $(\mathrm{mm})$ & Structural column $(\mathrm{mm})$ \\
\hline A1 & $3080 \times 2770 \times 280$ & 0.2 & 172.48 & No & No \\
A2 & $3080 \times 2770 \times 280$ & 0.2 & 172.48 & No & $180 \times 180$ \\
A3 & $3080 \times 2770 \times 280$ & 0.2 & 172.48 & $920 \times 1000$ & $180 \times 180$ \\
\hline
\end{tabular}

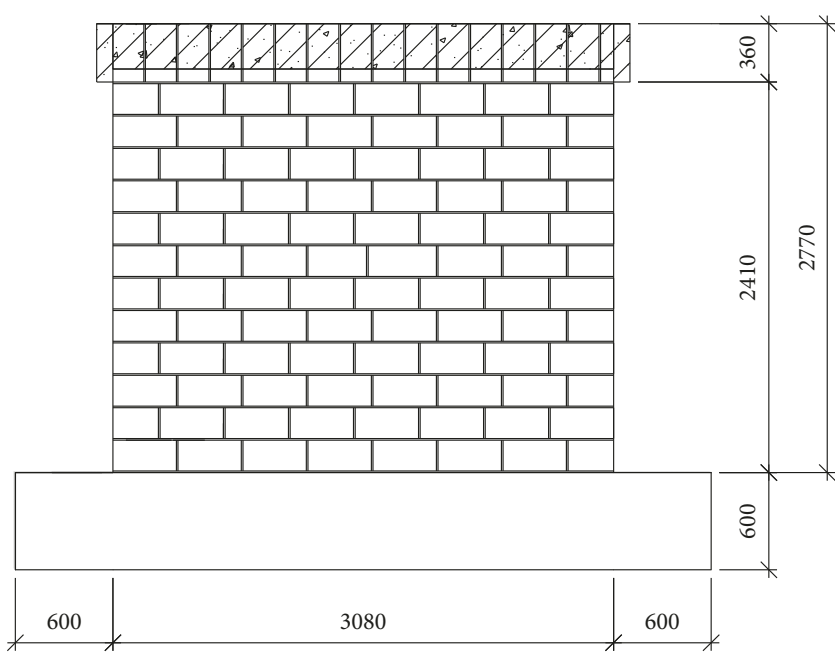

(a)

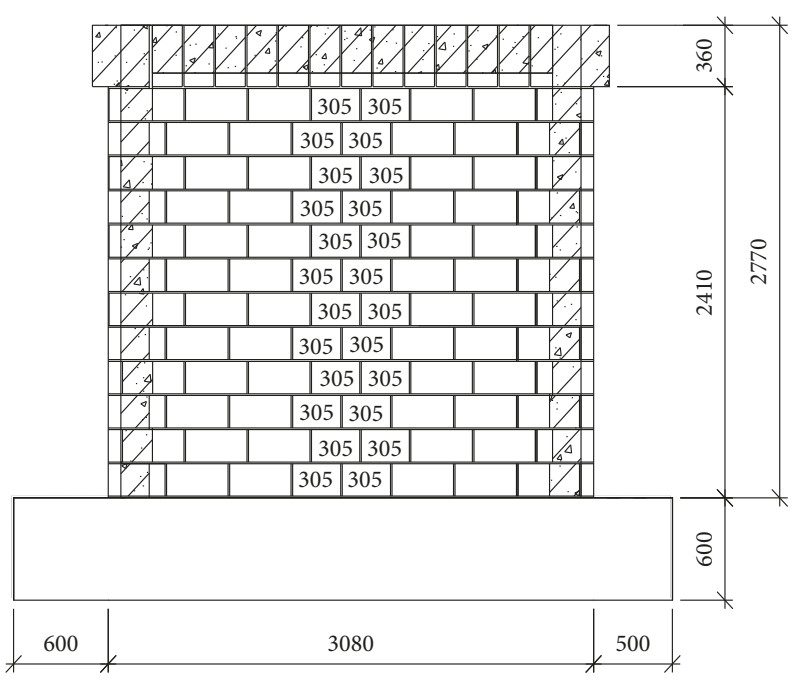

(b)

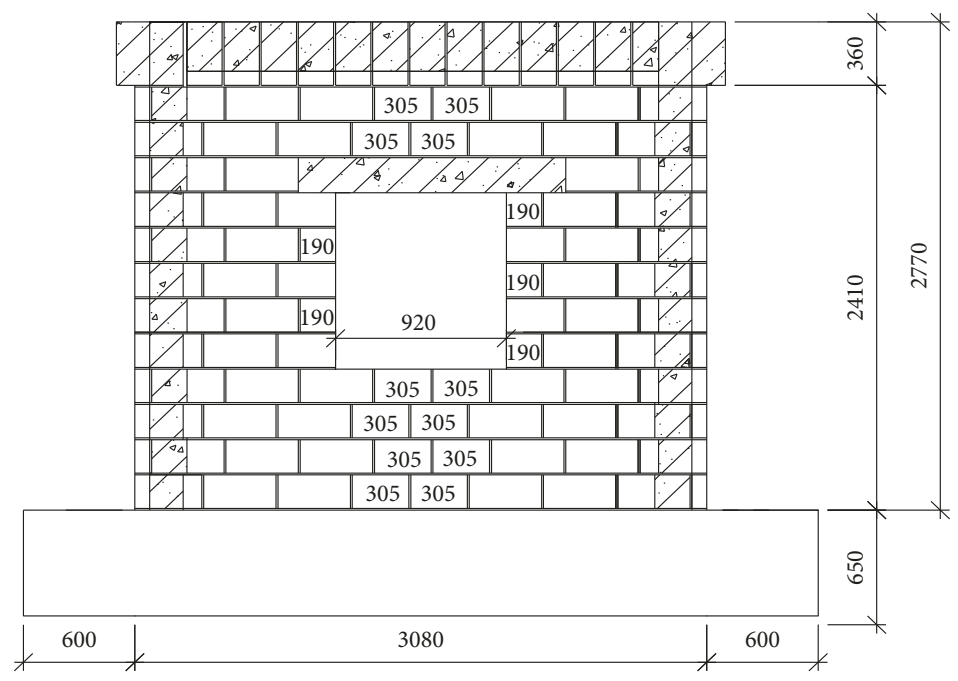

(c)

Figure 2: Elevation of test walls: (a) A1, (b) A2, and (c) A3.

TABLE 2: Material properties.

\begin{tabular}{lccc}
\hline Item & Longitudinal reinforcement (HRB400) & Stirrup reinforcement & Concrete grade $(\mathrm{MPa})$ \\
\hline Beam $400 \times 600 \mathrm{~mm}$ & $8 \phi 20$ & $\phi 8 @ 200$ & 30 \\
$200 \times 260 \mathrm{~mm}$ & $6 \phi 16$ & $\phi 8 @ 200$ & 25 \\
Column $200 \times 200 \mathrm{~mm}$ & $6 \phi 16$ & $\phi 8 @ 200$ & 25 \\
\hline
\end{tabular}

test was controlled by displacement, and three reversed cycles were considered for each displacement level.

The average value of the positive and negative displacements at the time of the initial crack is taken as the displacement control, and the displacement is rotated three times until the specimen load falls to the limit load of $85 \%$ after the end of the test. The loading system is shown in Figure 6.

3.4. Measuring Point Arrangement and Data Acquisition. The tested walls were instrumented with linear variable differential transducers (LVDTs) to monitor the 


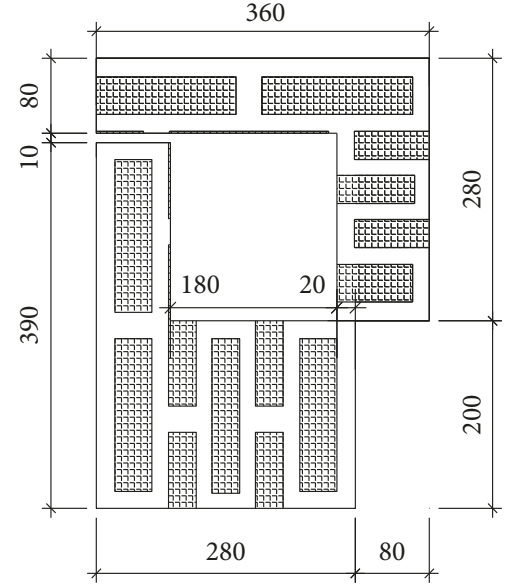

(a)

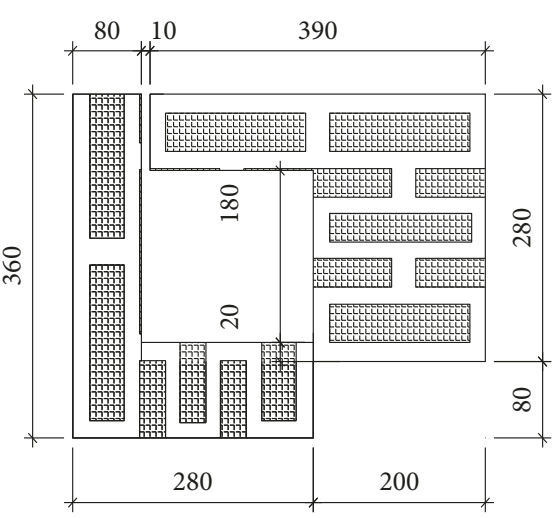

(b)

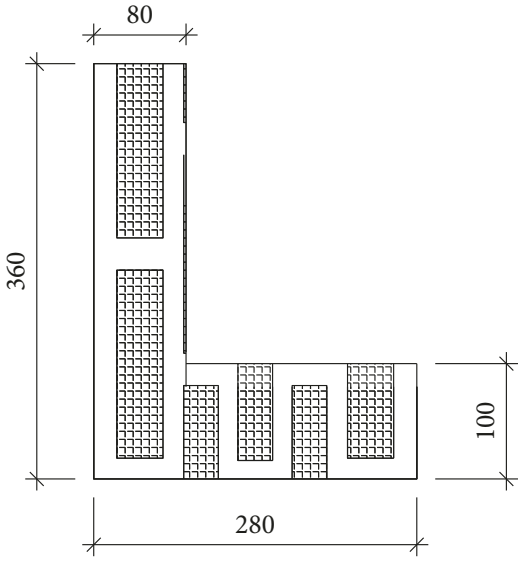

(c)

FiguRE 3: Dimensions of structural columns and ring beams. (a) Odd column construction layer. (b) Even columns construction layer. (c) Ring beam.

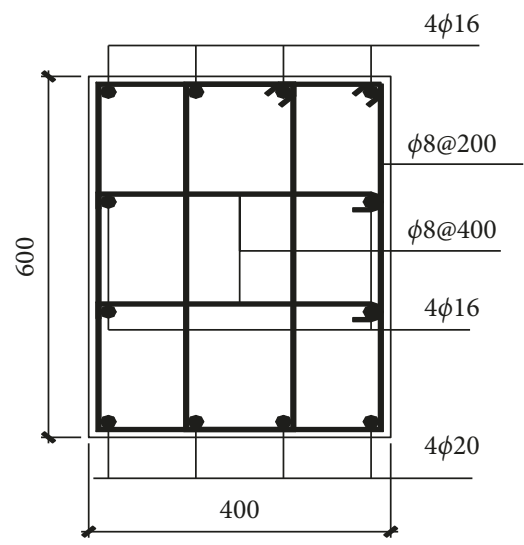

(a)

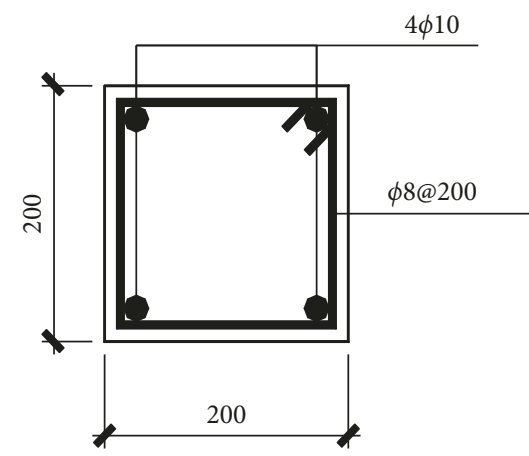

(b)

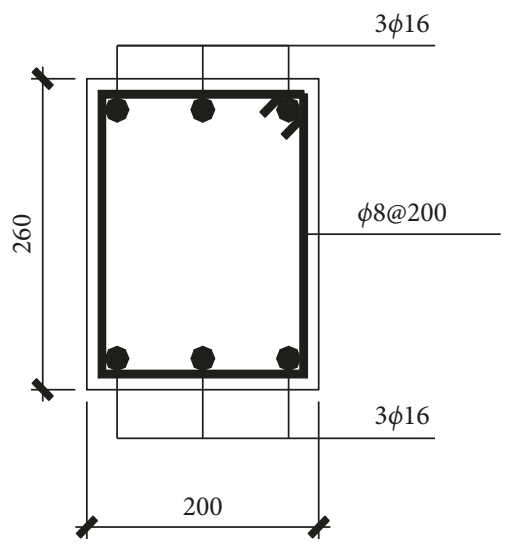

(c)

FIGURE 4: Reinforcement diagram of (a) ground beam, (b) structural column, and (c) ring beam.

displacement during the test. The displacement during testing was measured using LVDTs which was labeled from 1 to 7 and located as in Figure 7.

The displacement potentiometers were used to measure the vertical displacements, sliding, and shear displacements at different locations on the wall specimen. The specific arrangement of the displacements is shown in Figure 7.

\section{Experimental Results and Discussions}

In the course of the experiment, the generated cracks were highlighted with black and red which depict the cracks in the positive and negative directions, respectively, and the observation surface is positive. The left side of the specimen is pushed by the end, while the right side was subjected to pullpull. Section below illustrates the specimens cracking pattern at the testing end for three walls.

In specimen A1 (control), the horizontal load is first applied to $50 \mathrm{kN}$ and then loaded at a rate of $50 \mathrm{kN}$ per load stages. In the initial stage of loading, the $P-\Delta$ curve showed linear relation. When the horizontal load is pushed to $+100 \mathrm{kN}$, the $P-\Delta$ curve begins to show a small amount of bending. The first horizontal crack appears in the lower right corner of the wall, with a crack length of about $50 \mathrm{~mm}$ in the cycle ends.

When $\Delta=4 \mathrm{~mm}$, small ladder cracks appear in the lower left corner of the wall. When $\Delta=6 \mathrm{~mm}$, the horizontal cracks in the left and right roots remain stable after about $800 \mathrm{~mm}$. When $\Delta=8 \mathrm{~mm}$, the ladder cracks appear and develop from the lower right corner of the wall to the upper part of the wall, and the presence of horizontal cracks at the bottom layers of the wall is due to the tensile bond strength between the unit and mortar. When $\Delta=10 \mathrm{~mm}$, the fourth skin seam cracks extend from the outside to the inside until the whole is horizontally penetrated. When $\Delta=12 \mathrm{~mm}$, the fifth skin gray seam cracks in the whole through the middle of the wall continue to produce new cracks. 


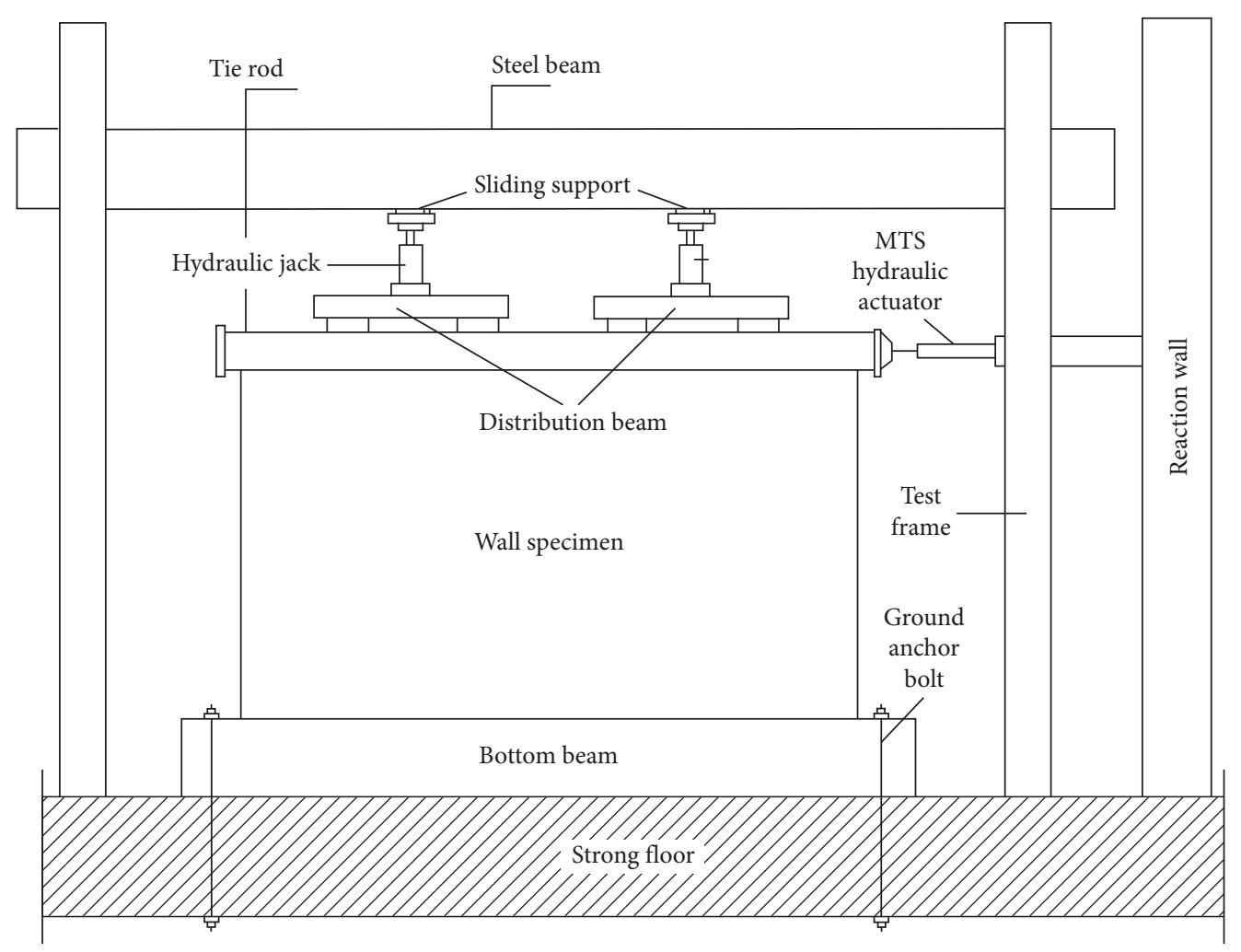

Figure 5: Schematic diagram of the test loading device.

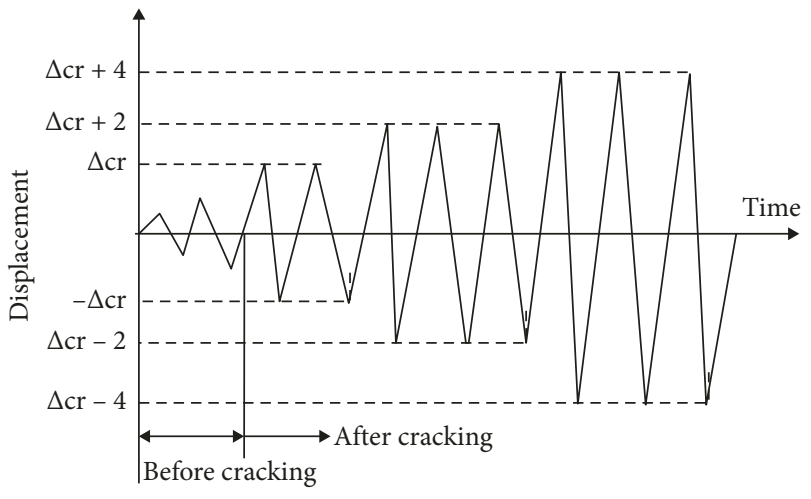

FIgURE 6: Test loading system.

When $\Delta=14 \sim 16 \mathrm{~mm}$, the ladder cracks in the middle of the wall are widened, extending in the diagonal direction of the wall, and the other diagonal line also appears with the ladder cracks. When $\Delta=18 \mathrm{~mm}$, the cracks expanded rapidly, the wall on the ground beam slips very obviously, and the wall and the top ring beam are separated from each other; this means that the wall cannot continue to carry the horizontal load. The failure mode and crack distribution of the wall are shown in Figure 8.

In wall A2, after the horizontal load is pushed to $+100 \mathrm{kN}$, the lower left corner of the structural column is divided into parts because of the occurrence of severe cracks (3-4 cracks), and the crack extends from the root of the structural column to the middle of the wall along the stepped

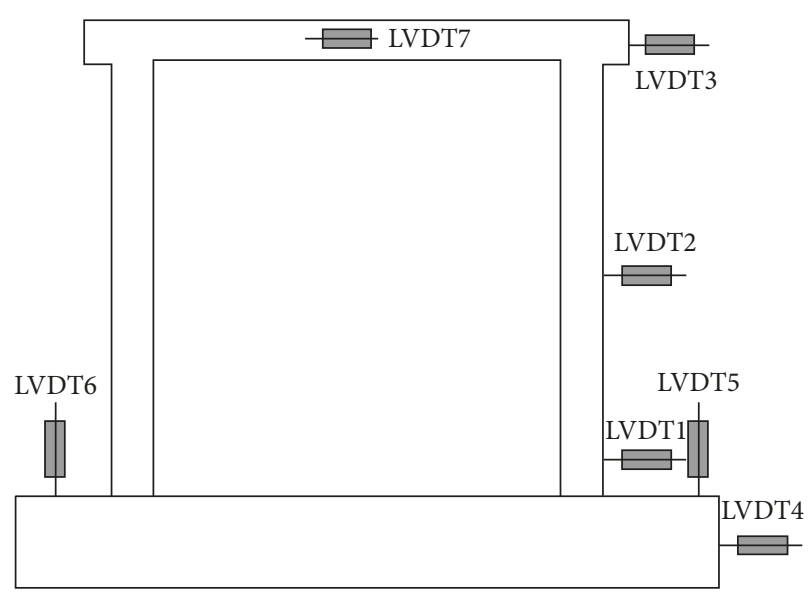

Figure 7: Displacement (LVDTs) plan layout.

gray seam, with displacement in the top part of the wall of approximately $2.0 \mathrm{~mm}$.

As the load is increased $(\Delta=4 \mathrm{~mm})$, some oblique diagonal cracks appear on the left side of the wall with the formation of " $\mathrm{X}$ " shape. A further increase in load $(\Delta=6 \mathrm{~mm})$ resulted in the widening of diagonal cracks as well as the initiation of new cracks from the existing cracks of the left side of the wall to the middle of the wall, and the right side of the structure of the column outside the masonry showed a few small cracks. At $8 \mathrm{~mm}$ displacement, long horizontal cracks across three blocks appeared at the bottom of the wall. As the loading continued to progress 


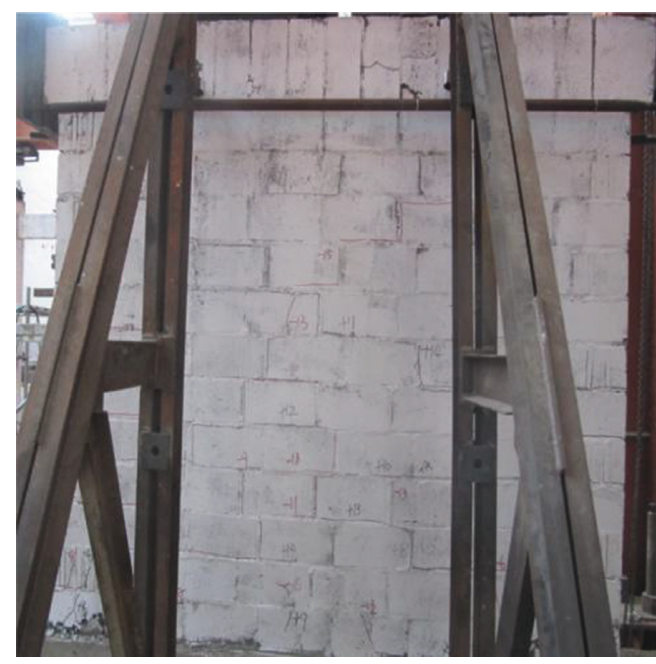

(a)

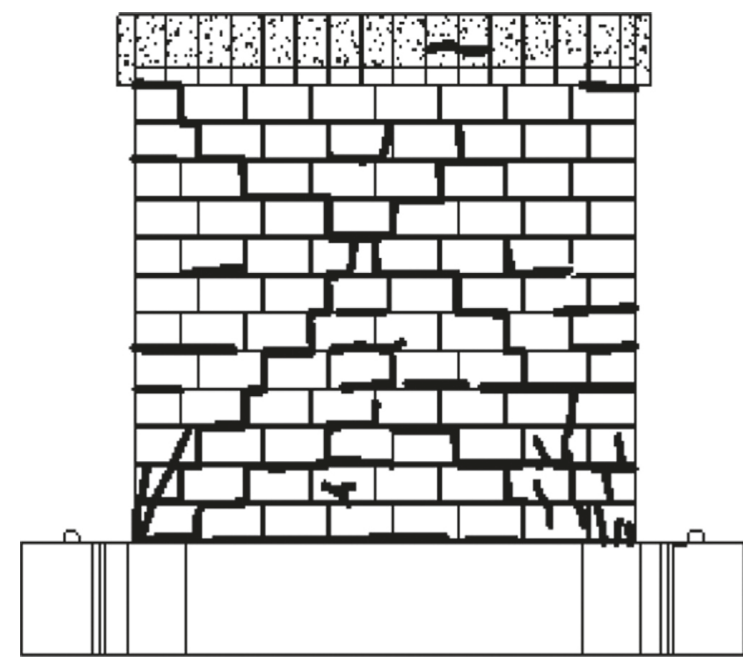

(b)

FIgURE 8: (a) Failure mode and (b) crack distribution of wall A1.

( $\Delta=10 \sim 12 \mathrm{~mm}$ ), the ladder cracks on the structural columns on both sides of the wall extend further, extending diagonally upward to add a horizontal crack to the existing one. At $\Delta=14 \mathrm{~mm}$, the horizontal cracks on the wall further widens as well as length increases. Furthermore, new ladder cracks that extend to the bottom of the ring beam are recorded at the wall displacement of $14 \sim 16 \mathrm{~mm}$. At $\Delta=20 \mathrm{~mm}$, new diagonal cracks initiate, and the original cracks increase in length and width, with the vertical angle at the corners of the wall with a maximum width of $5 \mathrm{~mm}$. Finally, a part of the wall block is crushed and peeled off at a wall displacement of approximately $22 \mathrm{~mm}$. Bearing capacity of this decreased to $85 \%$, at the end of the test compared to the control. The failure mode and crack distribution of the wall are shown in Figure 9.

Specimen A3 has an opening of $920 \times 1000 \mathrm{~mm}$; the opening was covered by prefabricated reinforced concrete beams with $1410 \mathrm{~mm}$ length and reinforced by $4 \phi 10$ as longitudinal reinforcement and stirrups of $\phi 8 @ 200 \mathrm{~mm}$. When the horizontal load is pushed to $+150 \mathrm{kN}$, first horizontal crack is appeared in the outer masonry of the left side of the structural column, with a wall displacement of $2.0 \mathrm{~mm}$. In this cycle, cracks on the left side of the structural column extend to the bottom side.

As the load is increased $(\Delta=6 \mathrm{~mm})$, a diagonal crack passing through the center of the opening forms and two additional cracks form in the lower right corner and in the bottom parts of the opening during the application of load. As the loading continues to progress with $\Delta=8 \mathrm{~mm}$, the cracks widen with several minor cracks appearing along the beam with two others horizontal cracks. At $\Delta=10 \mathrm{~mm}$, diagonal cracks with the direction of $45^{\circ}$ on the upper and lower corners are formed, and the width of the existing cracks at the corners of the opening obviously deepens.

At $\Delta=12 \mathrm{~mm}$, the width of the crack around the opening further increases, and many ladder cracks in the vicinity of the opening appear. When the last cycle is shifted to $14 \mathrm{~mm}$, the outer block of the left side of the structural column gets crushed, and the vertical steel bars of the walls yield displacement. The load-carrying capacity of the wall drops below $85 \%$ of the ultimate load, and the test is terminated. The broken form and crack distribution of the wall are shown in Figure 10.

The ultimate strength of the walls is governed by the flexural yielding of the vertical reinforcement and the compressive crushing of the toe regions in the masonry wall.

\subsection{Damage Process}

4.1.1. Damage Characteristics. By comparison of the test walls, in the wall without nonstructural column, cracks firstly appear in the middle and in the lower parts of the wall and then along the diagonal direction to form a pair of " $\mathrm{X}$ "type stepped joints; later, the top of the ring beam and wall body were separated from each other, and the ground beam slips very obviously. As the load is increased, the wall intersects the stepped cracks with $45^{\circ}$ and eventually breaks down along the main diagonal, and this is due to stress concentrations and local cracking about the opening edges. With the decrease in the horizontal load, the cracks on the four corners of the opening continuously develop in the diagonal direction which results in a severe collapse.

4.1.2. Destruction Phase Division. Structurally, the test walls are different, but the crack patterns of the walls show a similar trend to " $\mathrm{X}$ "-type cracks as shear damage; however, the maximum measured crack width for wall A3 beams is higher. Furthermore, the attained ultimate loads are lower than that of the walls A1 and A2. Generally, failure processes go through three stages [17]; firstly, elastic stage, which represents the first horizontal cracks with the load-deflection $(P-\Delta)$ curve near to a straight line. Secondly, elastoplastic stage, in this stage, the curve starts to show some reasonable inclination with a large number of cracks, low stiffness, and high hysteresis loop area. Thirdly, destruction phase, main 


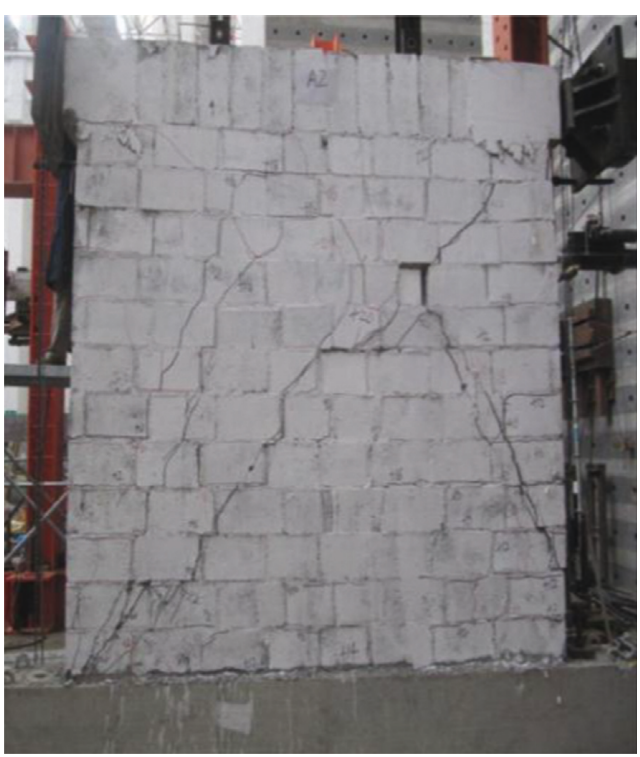

(a)

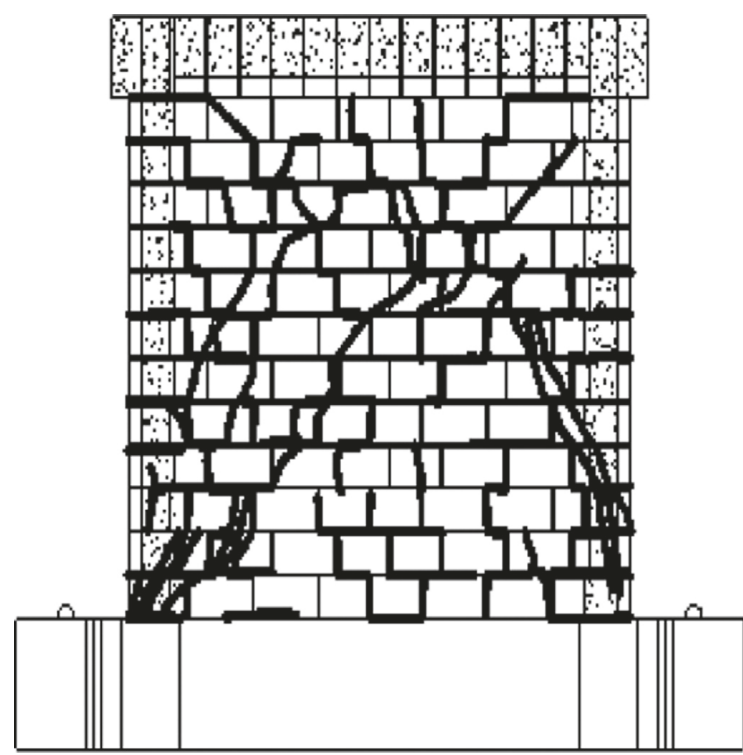

(b)

FIgURE 9: (a) Failure mode and (b) crack distribution of wall A2.

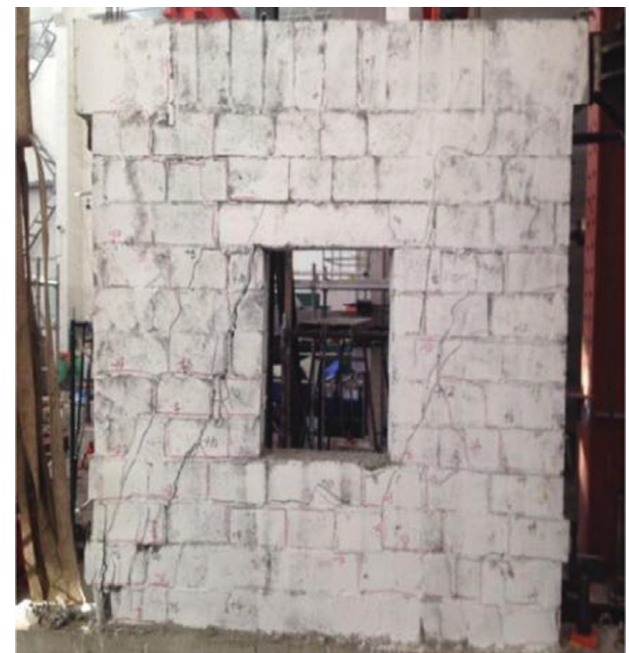

(a)

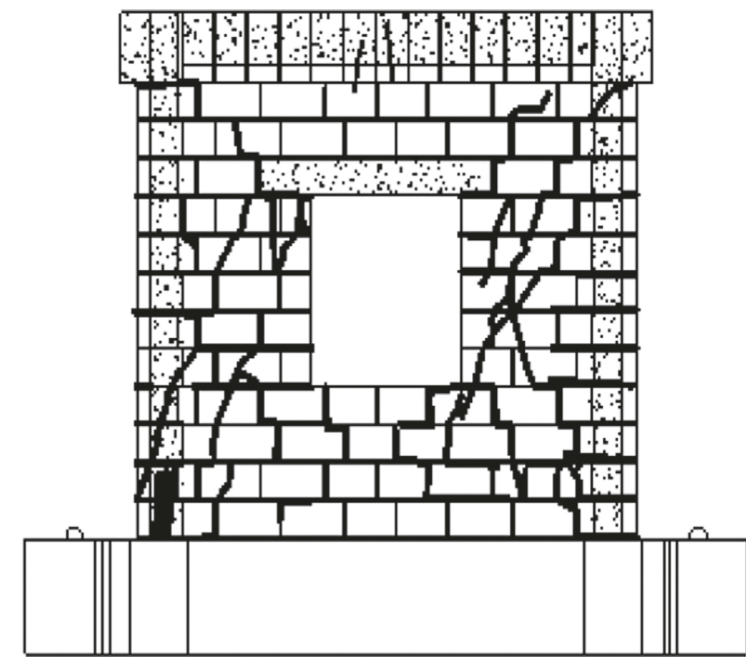

(b)

FIGURE 10: (a) Failure mode and (b) crack distribution of wall A3.

cracks significantly widens and extends, and the wall appears out of the block phenomenon. During this period, the vertex of the $P-\Delta$ curve decreases, and the wall deformation increases significantly with serious crushing.

\subsection{Test Results and Analysis}

4.2.1. Load and Deformation. The load-deflection curves and corresponding ultimate load, damage load, failure load, and the maximum displacement (load and displacement corresponding to the sudden change of the curves) of the test walls are shown in Table 3.

The results in Table 3 show no much difference, and this is due to the presence of the outer column wrapped around the $60 \mathrm{~mm}$ thick block, resulting in a slight difference in cracking. The nonstructural wall cracking load is closest to the ultimate load, and the bearing capacity decreases rapidly after cracking. In the wall with the new structural columns, regardless of cracking load, ultimate load, or damage load, bearing capacity is large compared to the control wall, and this attributes to the presence of structural columns which supports the part of the horizontal load. In the case of the wall with an opening, the ultimate displacement and damage displacement of the wall are small, which is due to the existence of stress in the corners of the opening leads to decreasing of stiffness and deformation capacity.

The hysteresis curve of each wall is shown in Figure 11. The hysteresis curves of the masonry wall usually have four 
TABLE 3: Characteristics of the load and displacement response of the wall.

\begin{tabular}{lcccccc}
\hline Wall ID & $\begin{array}{c}\text { Cracking } \\
\text { load }(\mathrm{kN})\end{array}$ & $\begin{array}{c}\text { Cracking } \\
\text { displacement }(\mathrm{mm})\end{array}$ & $\begin{array}{c}\text { Ultimate } \\
\text { load }(\mathrm{kN})\end{array}$ & $\begin{array}{c}\text { Limit } \\
\text { displacement }(\mathrm{mm})\end{array}$ & $\begin{array}{c}\text { Yield } \\
\text { load }(\mathrm{kN})\end{array}$ & $\begin{array}{c}\text { Destroying } \\
\text { displacement }(\mathrm{mm})\end{array}$ \\
\hline A1 & 125 & 4.1 & 188.8 & 14.45 & 160.5 & 16.1 \\
A2 & 145 & 4.0 & 343.5 & 18.01 & 292 & 182 \\
A3 & 110 & 2.8 & 212.5 & 9.02 & 180.6 & 12.1 \\
\hline
\end{tabular}

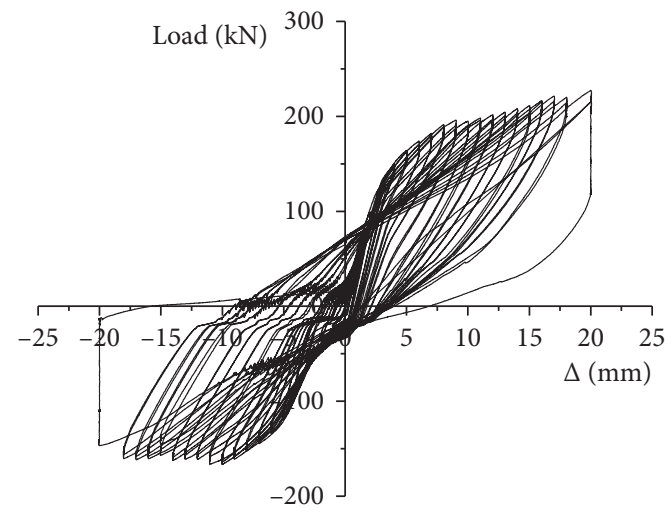

(a)

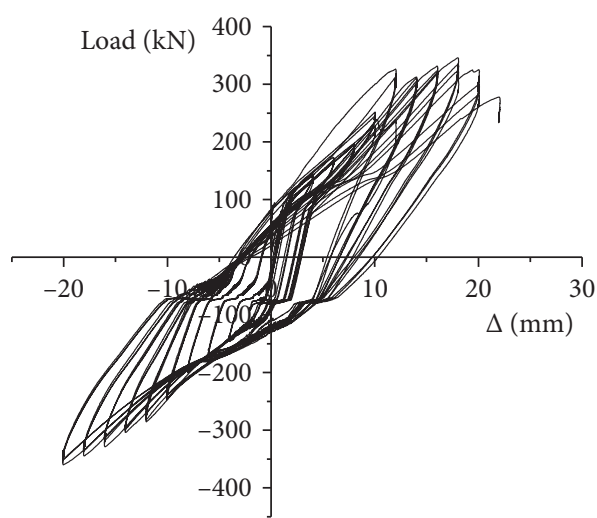

(b)

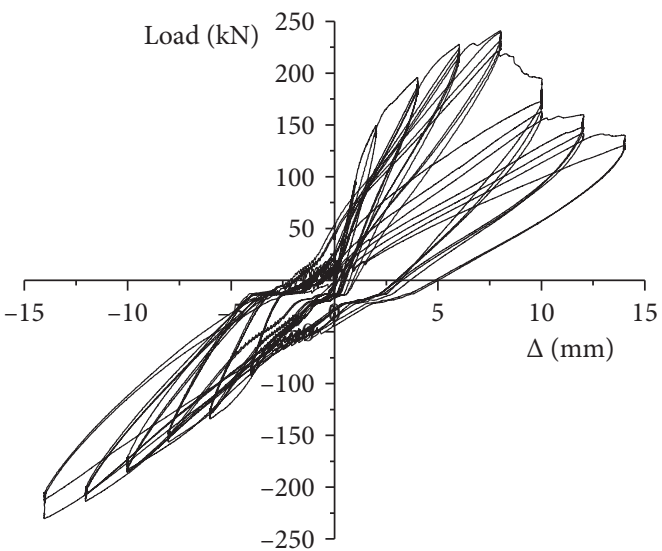

(c)

Figure 11: Load-displacement hysteresis diagrams for test walls: (a) A1, (b) A2, and (c) A3.

basic forms under different damage mechanisms: spindle, arc, anti-S, and anti-Z.

According to Figure 11, before the cracking of the wall, the horizontal displacement of the wall is very small, the hysteresis curve is approximately straight, the stiffness of the specimen is basically the same after the unloading, the hysteresis loop is long, and the area is small, indicating that the wall is in the elastic state. After the cracking load is reached, the wall cracks gradually increase and widen, the stiffness of the specimen decreases, and the hysteresis curve gradually tilts toward the displacement axis, and the enclosed area increases. The residual deformation increases with the number of load cycles, and the corresponding hysteresis curve begins to show a more obvious bending. The shape of the hysteresis loop changes to the fusiform shape, showing obvious effect, and the wall energy dissipation capacity is enhanced.
After the horizontal load of the wall reaches the ultimate load, the main crack of the " $\mathrm{X}$ "-shaped ladder gradually forms on the wall, the slip between the blocks is obvious, the hysteresis loop changes from the fusiform to the arch or the anti-S-shaped, and residual deformation after unloading is larger; this time the wall can no longer bear a larger load, and this means the wall is in the plastic condition.

Wall A1 fails due to shear failure because the wall produced two lines through the horizontal cracks, and the deformation of the wall is mainly due to the slip along the seam. A2 belongs to the shear friction-shear pressure composite damage, and the deformation of the wall is due to ladder cracks and damage. After entering the elastic-plastic stage, the A2 hysteresis curve is more obviously in spindle shape, the hysteresis loop gradually shows "pinch" effect, the wall's energy consumption is stronger, and the energy is 
mainly by the two sides of the structural column to dissipate, which effectively improves the safety of the wall. Wall A3 is fails due to shear-shear composite failure. With the increase of the horizontal load, the hysteresis loop is more obvious from the early fusiform to arcuate, and the hysteresis loops are decreased which means there is a reduction in the structure of the energy consumption.

4.2.2. Skeleton Curves. The skeleton curve can reflect the key mechanical characteristics of the wall under low-cyclic loadings, such as cracking load, ultimate bearing capacity, deformation capacity, and ductility [10]. According to the hysteresis curve obtained above, the envelope of the successive points of the load in the same direction is the skeleton curve as shown in Figure 12.

4.2.3. Normalized Curve Comparison. The normalized skeleton curves of walls are shown in Figures 13(a)-13(c). The normalized skeleton curve from the three wall statistics is shown in Figure 13(d).

According to the normalized skeleton curve of three energy-saving concrete self-insulation block walls, it can be seen that the curve can be divided into three working stages, among which the characteristic points are the average of the test specimens:

(1) Section $0 A$ is the elastic phase, and the equation for the elastic phase is $P / P_{\mathrm{u}}=2.472 \Delta / \Delta_{\mathrm{u}}$. The stiffness of the section is defined as the initial stiffness $K_{0}$ of the skeleton, then $K_{0}=2.472$.

(2) Section $A B$ is an elastoplastic stage, and the equation for the elastoplastic stage is $P / P_{\mathrm{u}}=0.594 \Delta / \Delta_{\mathrm{u}}+$ 0.406 . When the crack from the specimen reaches the ultimate load, the stiffness of the specimen decreases, and the slope of the section $\mathrm{AB}$ is the stiffness $K_{1}$, then $K_{1}=0.594$.

(3) Section BC is the descending phase, and the equation for the descending phase is $P / P_{\mathrm{u}}=-1.128 \Delta / \Delta_{\mathrm{u}}+$ 2.128. At this time, the component reaches the ultimate load after the bearing capacity begins to decrease, and the stiffness $K_{2}$ is the negative slope of the line BC, then $K_{2}=1.128$.

4.2.4. Stiffness Degradation. The mechanical phenomenon of the wall is called the degeneration of the stiffness, and the degradation rate of the wall stiffness can be regarded as another important index worthy of study. The deformation of the wall can be fully developed, the stiffness and displacement change, and the number of cycles is closely related. As the masonry structure of the larger dispersion, the stiffnesses of the two directions are different. Therefore, under the cyclic load of each wall, the ratio of the sum of the absolute values of the load in the two directions of the wall and the absolute value of the displacement is taken as the stiffness under the load as follows:

$$
K_{i}=\frac{\left|P_{i}\right|+\left|-P_{i}\right|}{\left|\Delta_{i}\right|+\left|-\Delta_{i}\right|},
$$

where $K_{i}$ is the stiffness at level $i$ load; $P_{i}$ and $-P_{i}$ are the forward and reverse horizontal load values under the $i$-th load; and $\Delta_{i}$ and $-\Delta_{i}$ are the forward and backward horizontal displacement values under level $i$ load.

The final stiffness degradation curve is fitted with a power function and illustrated in Figure 14. The regression function is shown in Table 4.

4.2.5. Ductility Performance. Ductility is the ability of the structure to withstand deformation after exceeding the elastic limit which indicates the seismic performance of the structural members. Greater ductility means that the member can provide the ability to dissipate the seismic energy and the plastic deformation. The ductility coefficient is the ratio of maximum deflection at ultimate to the yielding deflection. The higher ductility coefficient is attributed to the lower deflection at yielding load and higher deflection at failure load [19].

4.2.6. Displacement Ductility Ratio. In general, the yield displacement of the masonry structure is difficult to be determined by a simple method, so the displacement ductility coefficient of the masonry structure is usually calculated using the following expression:

$$
u=\frac{\Delta_{\mathrm{u}}}{\Delta_{\mathrm{cr}}},
$$

where $\Delta_{\mathrm{u}}$ is the absolute value in both directions and $\Delta_{\mathrm{cr}}$ is the displacement at the time of cracking.

4.2.7. The Limit Displacement Angle. The limit displacement angle $R_{\mathrm{u}}$ is defined as the ultimate deformation capacity of the wall, and the $H$ value of the wall plus half depth of the top beam, that is, $2590 \mathrm{~mm}$; it can be calculated from Equation (3). The ductility and ultimate displacement angles of each specimen are shown in Table 5:

$$
R_{\mathrm{u}}=\frac{\Delta_{\mathrm{u}}}{H}
$$

Table 5 shows that the structural column has an ultimate ductility coefficient and an ultimate displacement angle, which indicates that the structural column has a certain influence on the ductility of the wall. The presence of the opening in specimen A3 leads to decrease in wall ductility compared to that in $\mathrm{A} 2$ and $\mathrm{A} 1$.

\subsection{The Energy Dissipation Characteristics of the Specimens.} The physical meaning of energy consumption refers to the work done by the restoring force of the structure in the seismic response, which reflects the ability of the structure to absorb energy and plays a leading role in the inelastic deformation of the structure. In this paper, Jacobson's equivalent viscous damping coefficient is used to represent the energy dissipation capacity of the specimen [20]. The energy consumption ratio often reflects the energy 


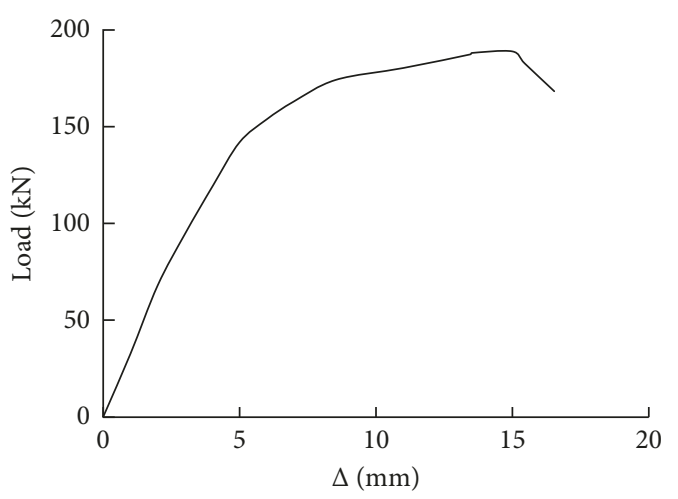

(a)

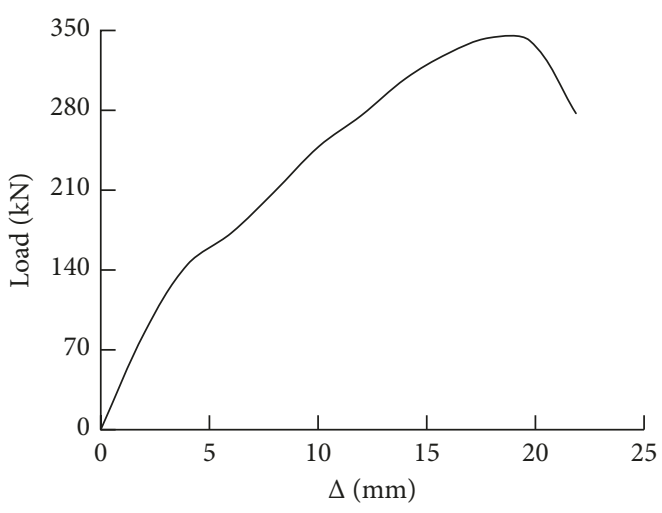

(b)

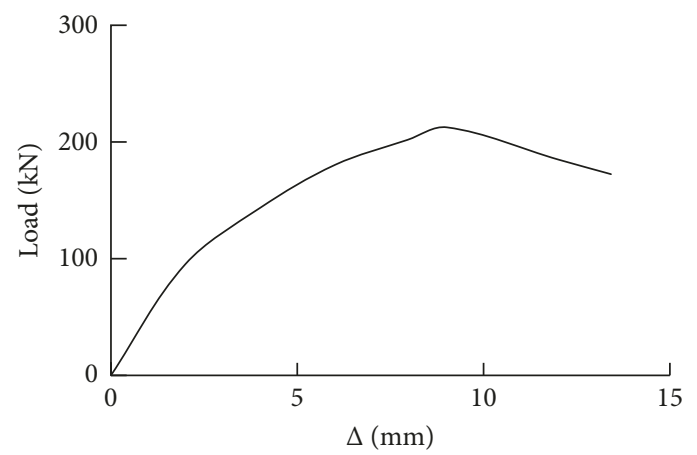

(c)

Figure 12: Skeleton curves for all wall specimens: (a) A1, (b) A2, and (c) A3.

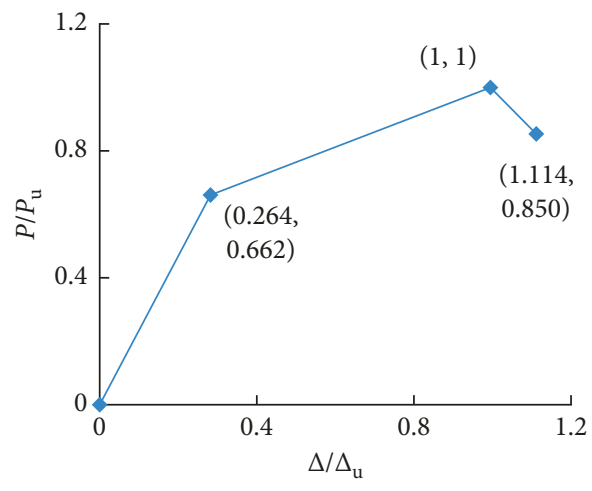

(a)

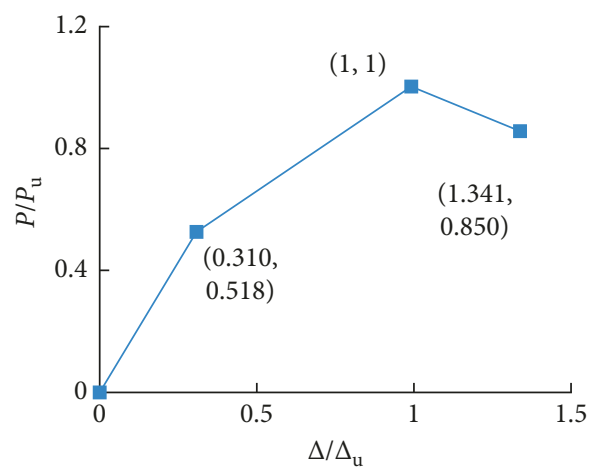

(c)

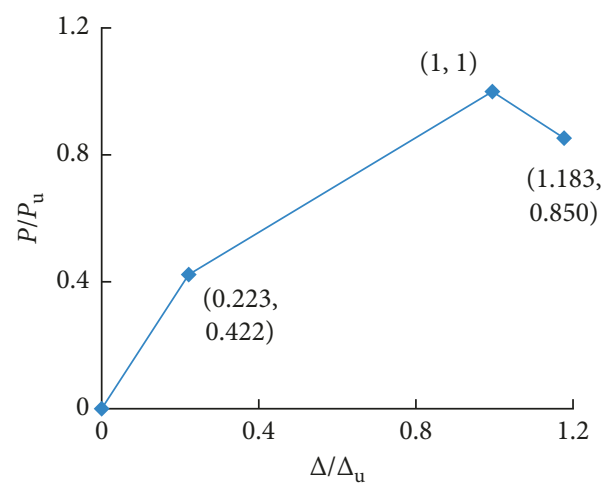

(b)

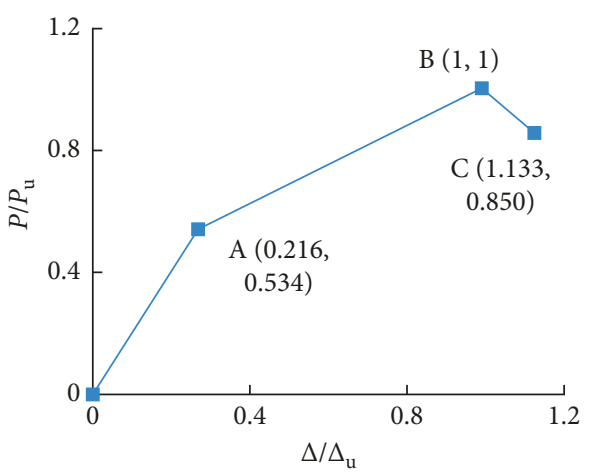

(d)

Figure 13: Normalized skeleton curves: (a) wall A1, (b) wall A2, (c) wall A3, and (d) all walls. 


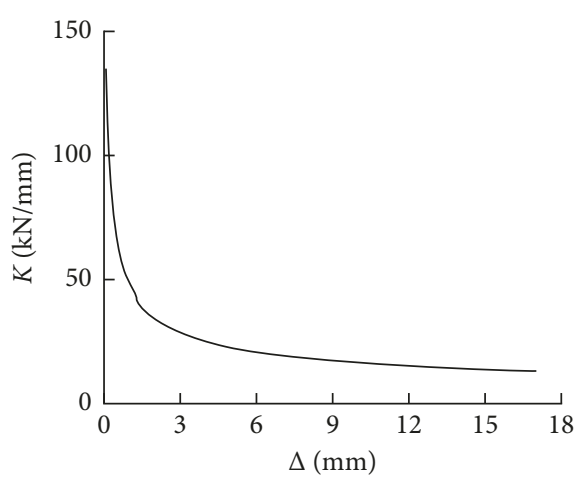

(a)

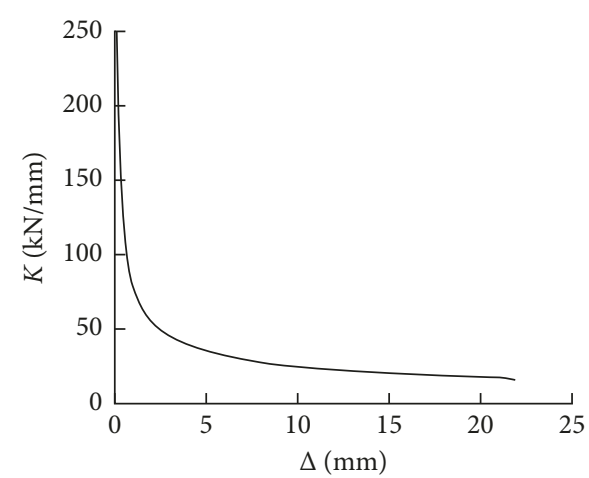

(b)

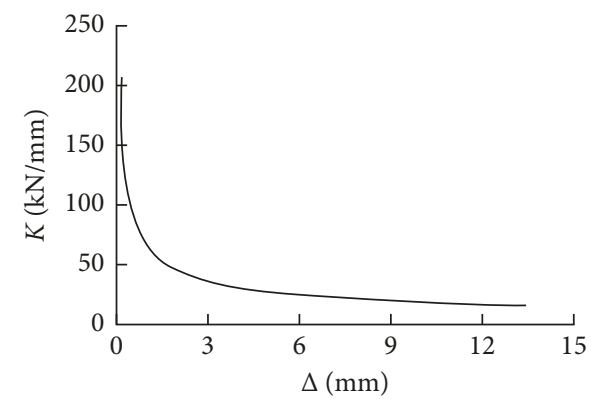

(c)

FiguRe 14: Degradation curves for all wall stiffnesses: (a) A1, (b) A2, and (c) A3.

TABLE 4: Stiffness-displacement quasi-curve.

\begin{tabular}{|c|c|c|c|}
\hline Specimen number & Initial stiffness $(\mathrm{kN} / \mathrm{mm})$ & Stiffness degradation power function & Correlation coefficient \\
\hline $\mathrm{A} 1$ & 135 & $y=47.582 x^{-0.458}$ & 0.934 \\
\hline $\mathrm{A} 2$ & 251 & $y=78.306 x^{-0.512}$ & 0.922 \\
\hline A3 & 218 & $y=64.918 x^{-0.527}$ & 0.938 \\
\hline
\end{tabular}

TABle 5: Ductility ratio and ultimate displacement angle of specimens.

\begin{tabular}{lccccc}
\hline $\begin{array}{l}\text { Specimen } \\
\text { number }\end{array}$ & $\begin{array}{c}\text { Cracking displacement, } \\
\Delta_{\mathrm{cr}}(\mathrm{mm})\end{array}$ & $\begin{array}{c}\text { Limit displacement, } \\
\Delta_{\mathrm{u}}(\mathrm{mm})\end{array}$ & $\begin{array}{c}\text { Wall height, } \\
H(\mathrm{~mm})\end{array}$ & $\begin{array}{c}\text { Displacement } \\
\text { ductility ratio }\end{array}$ & $\begin{array}{c}\text { Limit } \\
\text { displacement angle }\end{array}$ \\
\hline A1 & 4.1 & 14.45 & 2590 & 3.52 & $1 / 179$ \\
A2 & 4.0 & 18.01 & 2590 & 4.5 & $1 / 144$ \\
A3 & 2.8 & 9.02 & 2590 & 3.2 & $1 / 287$ \\
\hline
\end{tabular}

dissipation characteristic of the structure. The energy dissipation ratio of each cycle is expressed by the area characteristic of the hysteresis loop (Figure 15). The energy consumption ratio $\psi$ of each cycle and the equivalent viscous damping ratio are calculated from Equations (4) and (5) and tabulated in Table 6:

$$
\begin{aligned}
& \psi=\frac{S_{\mathrm{ABC}}+S_{\mathrm{CDA}}}{S_{\mathrm{OBE}}+S_{\mathrm{ODF}}} . \\
& \zeta_{e}=\frac{\psi}{2 \pi} .
\end{aligned}
$$

From Table 6, it can be found that the energy consumption of the structure of the wall is stronger, and the effect of the opening on the energy dissipation of the wall is

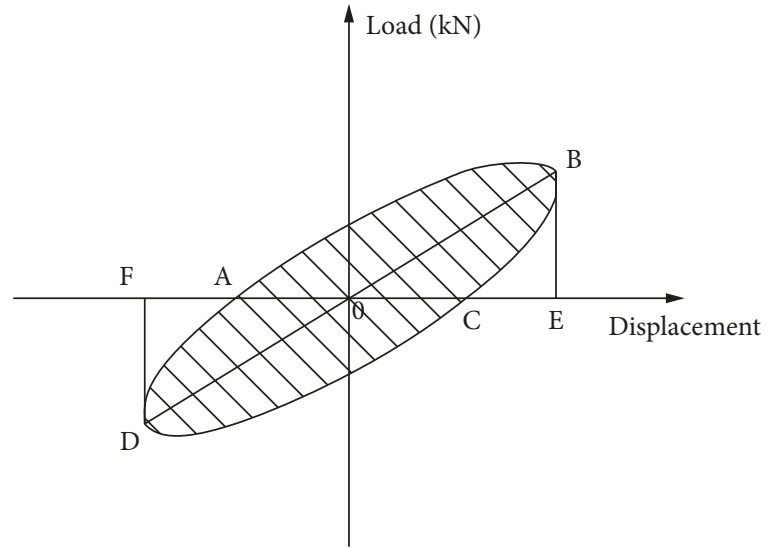

FIGURE 15: Equivalent viscous damping calculation. 
TABLE 6: Sample energy dissipation ratio and equivalent viscous damping ratio.

\begin{tabular}{lcccccc}
\hline \multirow{2}{*}{ Specimen number } & \multicolumn{3}{c}{ Energy consumption ratio, $\psi$} & \multicolumn{3}{c}{ Equivalent viscous damping ratio } \\
& Cracking state & Limit state & The state of destruction & Cracking state & Limit state & The state of destruction \\
\hline A1 & 0.55 & 0.727 & 0.793 & 0.088 & 0.116 & 0.126 \\
A2 & 0.571 & 0.973 & 1.112 & 0.091 & 0.155 & 0.177 \\
A3 & 0.426 & 0.474 & 0.584 & 0.068 & 0.075 & 0.093 \\
\hline
\end{tabular}

greatly affected. In general, the energy dissipation of the wall increases with the increase of the displacement of the specimen, which indicates that the wall is cracked and the friction surface increased.

\subsection{Strain Analysis of Structural Columns and Seismic Bearing} Capacity. It can be seen from the experimental phenomena that the first fracture of the specimen is found in the root of the structural column, where only the steel strain of the column is described, and the typical displacement-strain curve is shown in Figure 16. According to the steel material, when the strain reaches 2000 , the rebar enters the yield state. It can be seen from the curve that the initial stiffness of the wall is large before the wall is cracked, and the strain of the longitudinal reinforcement in the structural column is very small. When the wall is cracked, the internal force of the structural column is growing faster. When the cracks penetrate the wall, the longitudinal reinforcement of the structural column reaches the yield strength, but because of the restraint effect of the longitudinal reinforcement of the structural column, the damaged wall does not collapse and reaches the target of cracking.

It can be found from the figure that the longitudinal reinforcement strain of the structural column in the elastic stage is symmetrical when the positive load is applied. The entry of the steel bar into the plastic force stage, mainly for the tensile strain, shows that the impact of shear on the walls $\mathrm{A} 2$ and $\mathrm{A} 3$ in the plastic phase is greater than the impact of bending.

The main factors that affect the seismic shear capacity of new concrete self-insulation block masonry are block and mortar strength, vertical compressive stress, aspect ratio, presence or absence of structural column, opening size and geometry, and masonry quality. In this experiment, the seismic performance of the new energy-saving masonry system is studied by using the structural column and the opening as the main parameter. When the bearing capacity of the masonry is calculated, the insulation block which acts as the template on the outside of the structural column is neglected. Only the concrete part of the structural column is considered. The size of the structural column is $180 \mathrm{~mm} \times 180 \mathrm{~mm}$, and the opening size is $920 \mathrm{~mm} \times 1000 \mathrm{~mm}$.

\section{Design Index of Energy-Saving Self- Insulation Block Masonry Strength}

Table 7 shows the average strength of the new energy-saving self-insulation block strength of the test walls.

\subsection{Seismic Shear Capacity of the Walls}

5.1.1. Seismic Bearing Capacity of Nonstructural Masonry. There are two basic theories at home and abroad about the failure mechanism of masonry structure: the main tensile stress theory and the shear friction theory. The main tensile stress under the composite force is more than that of the masonry structure (mainly against the shear strength of the stepped section in the masonry section without vertical load). And the shear failure, caused by China's "Building Seismic Design Code" by statistical analysis of earthquake damage, has used the main tensile stress theory to calculate the shear strength. On the contrary, it can be seen from the experimental phenomena that the damage of the A1 wall belongs to the shear damage because the wall produces two penetrating horizontal cracks, the deformation of the wall mainly comes from the slip along the beam, the shear strength of the masonry force is the sum of the bond strength of the mortar layer and the normal pressure. The "masonry structure design specification" is adopted, and the shear rule is used as the failure criterion of the masonry structure. Bearing capacity of the sheared member with shear force is shown in Equations (6) and (7):

$$
\min \left\{\begin{array}{l}
V \leq \frac{1}{r_{\mathrm{RE}}} f_{v E} A \quad \text { (variable coefficient - shear friction theory), } \\
V \leq \frac{\left(f_{v}+\alpha \mu \sigma_{0}\right) A}{r_{\mathrm{RE}}} \quad \text { (principal tensile stress theory), }
\end{array}\right.
$$

where $V=$ seismic shear design value; $A=$ horizontal crosssectional area; $f_{v}=$ masonry shear strength design values, according to Table 7 used; $\alpha=$ correction factor, according to the adverse situation, when the concrete block masonry to take 0.66 ; and $\mu=$ shear pressure composite force influence coefficient; according to the adverse situation, then 


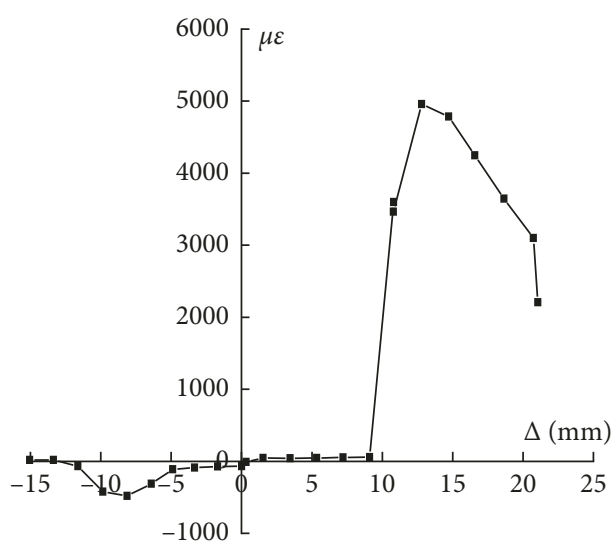

(a)

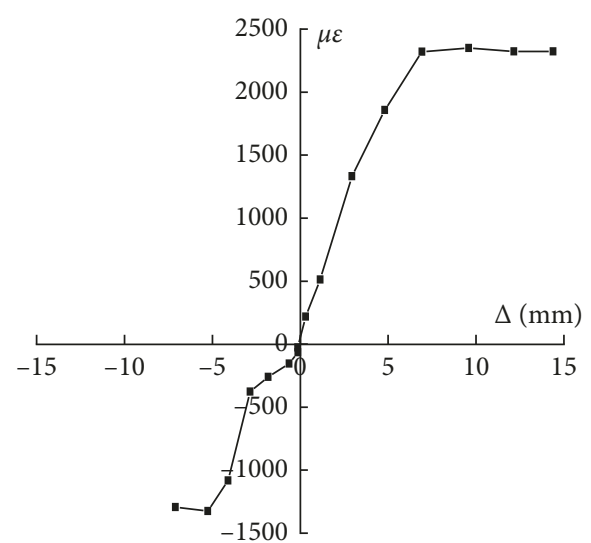

(b)

FIgURE 16: Longitudinal reinforcement root strain diagram: (a) A2 and (b) A3.

TABLE 7: Average strength and design value of compressive strength and shear strength of new energy-saving block masonry (MPa).

\begin{tabular}{lccccc}
\hline \multirow{2}{*}{$\begin{array}{l}\text { Strength category } \\
\text { Block } f_{1}\end{array}$} & \multicolumn{2}{c}{ Measured value } & Average calculation formula & Average value $f_{m}$ or $f_{v, m}$ & Design value $f$ or $f_{v}$ \\
\hline $\begin{array}{l}\text { Compressive strength } \\
\text { Shear strength }\end{array}$ & 5.92 & 10.0 & $f_{m}=0.72 f_{1}^{0.61}\left(1+0.07 f_{2}\right)$ & 3.7 & 2.4 \\
& & & $f_{v, m}=0.165 \sqrt{f_{2}}$ & 0.52 & 0.1 \\
\hline
\end{tabular}

$$
\mu=0.23-0.065 \frac{\sigma_{0}}{f}
$$

where $f=$ masonry compressive strength design value; $\sigma_{0}=$ the mean compressive stress of the horizontal section produced by the permanent load design value shall not be greater than 0.8 ; and $f_{v E}=$ the design value of the shear strength of the masonry along the stepped cross section:

$$
f_{v E}=\xi_{N} f_{v} \text {, }
$$

where $f_{v}=$ nonseismic design of the masonry shear (pure shear) strength design values, according to Table 7 used, and $\xi_{N}=$ the influence coefficient of the normal stress on the shear strength of the block masonry is checked by the seismic code.

5.2. Seismic Shear Capacity of Concrete Column Block Masonry. The following equation is used for calculating the shear capacity of ordinary concrete self-insulation block masonry:

$$
\begin{aligned}
V= & \frac{1.5}{1+0.5(H / B)}\left[\left(f_{v 0, m}+a \mu \sigma_{y}\right)\left(1-0.21 \delta-1.3 \delta^{2}\right) A_{m}\right. \\
& \left.+0.03 f_{c} A_{c}+0.05 f_{y} A_{s}\right],
\end{aligned}
$$

where $V=$ shear capacity of structured column walls; $H=$ wall height; $B=$ wall width; $f_{v 0, m}=$ masonry average pure shear strength; $a=$ modification coefficients for different types of masonry, when $\gamma_{G}=1.2$ for brickwork 0.6 , for concrete block masonry 0.64 ; when $\gamma_{G}=1.35$, for brickwork 0.64 , for concrete block masonry $0.66 ; \mu=$ shear composite force influence coefficient, $\delta=$ opening ratio (ratio of the opening area to the wall area); $\sigma_{y}=$ vertical pressure; $A_{m}=$ partial cross-sectional area of masonry wall block; $f_{c}=$ the average compressive strength of concrete; $A_{c}=$ structure column cross-sectional area; $f_{y}=$ tensile strength of structural column; and $A_{s}=$ sectional area of the steel bar.

In summary, the calculated seismic shear capacity of $A 1$, A2, and A3 masonry is shown in Table 8.

According to the "seismic code," the model shear stress corresponding to different intensities is calculated using the bottom shear method according to the maximum value of the horizontal seismic impact coefficient (Tables 9 and 10).

5.3. Evaluation of Seismic Capacity. The experimental values, calculated values, and seismic shear forces of the three specimens are summarized in Table 11.

\section{Conclusions}

In this study, three new low-cycle cyclic loadings of new energy-saving concrete self-insulating load-bearing block walls energy-saving self-insulation were fabricated and tested. The results show that the wall failure process, failure modes, and other seismic performance indexes of the wall are studied, including hysteresis curve, skeleton curve, stiffness degradation, ductility, energy dissipation and seismic load, and other properties. The main conclusions are as follows:

(1) The special configuration of ECSB has advantages in both structural and thermal properties. The 
TABLE 8: Calculated values for seismic shear capacity of three test walls.

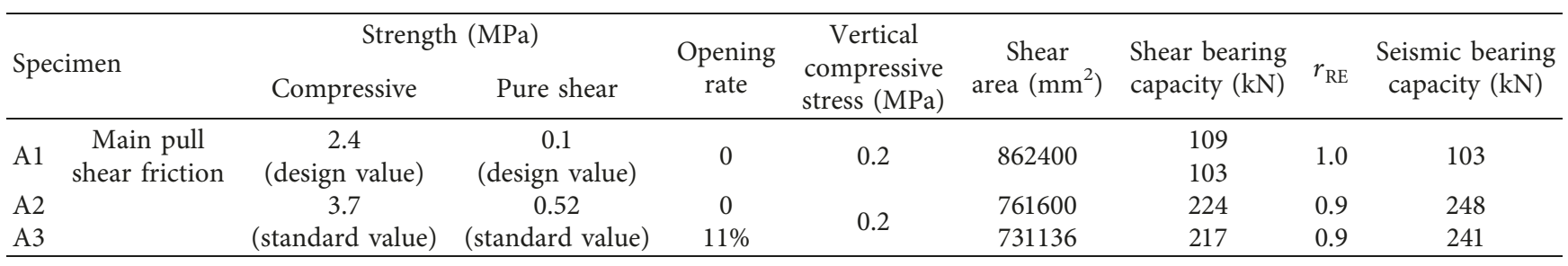

TABle 9: Maximum impact coefficient of horizontal earthquake $\left(\mathrm{cm} / \mathrm{s}^{2}\right)$.

\begin{tabular}{lccccc}
\hline & 7 degree & 7 degree $(0.15 \mathrm{~g})$ & 8 degree & 8 degree $(0.30 \mathrm{~g})$ & 9 degree \\
\hline Frequent occurrence & 0.08 & 0.12 & 0.16 & 0.24 & 0.32 \\
Basic value & 0.23 & 0.34 & 0.46 & 0.69 & 0.92 \\
Rare value & 0.5 & 0.72 & 0.90 & 1.20 \\
\hline
\end{tabular}

TABLE 10: Seismic shear force corresponding to seismic intensity $(\mathrm{kN})$.

\begin{tabular}{|c|c|c|c|c|c|c|c|c|c|c|}
\hline \multirow{3}{*}{ Wall ID } & \multirow{3}{*}{ Wall weight $(\mathrm{kN})$} & \multicolumn{9}{|c|}{ Seismic action of wall $(\mathrm{kN})$} \\
\hline & & \multicolumn{3}{|c|}{7 degree } & \multicolumn{3}{|c|}{8 degree } & \multicolumn{3}{|c|}{9 degree } \\
\hline & & Frequent & Basic & Rare & Frequent & Basic & Rare & Frequent & Basic & Frequent \\
\hline$\overline{\mathrm{A} 1}$ & 179 & 14.32 & 45.31 & 89.5 & 28.64 & 82.34 & 161.1 & 57.28 & 164.68 & 250.6 \\
\hline $\mathrm{A} 2$ & 197 & 28.64 & 90.62 & 156.6 & 31.52 & 90.62 & 177.3 & 63.04 & 181.24 & 275.8 \\
\hline A3 & 174 & 13.92 & 40.02 & 87 & 27.84 & 80.04 & 156.6 & 55.68 & 160.08 & 243.6 \\
\hline
\end{tabular}

TABLE 11: Calculated and experimental values of shear strength of specimens.

\begin{tabular}{lccccc}
\hline Wall ID & $\begin{array}{c}\text { Ultimate shear capacity } \\
\text { (test value) }(\mathrm{kN})\end{array}$ & $\begin{array}{c}\text { Seismic shear capacity } \\
\text { (calculated value) }(\mathrm{kN})\end{array}$ & $\begin{array}{c}\text { Test value/calculation value } \\
7 \text { degree }\end{array}$ & \multicolumn{2}{c}{$\begin{array}{c}\text { Basic earthquake action of wall } \\
(\mathrm{kN})\end{array}$} \\
\hline A1 & 188.8 & 103 & 1.83 & 45.31 & 82.34 \\
A2 & 343.5 & 248 & 1.39 & 90.62 & 90.62 \\
A3 & 212.5 & 150 & 1.42 & 40.02 & 80.68 \\
\hline
\end{tabular}

structural advantage is providing stronger bonds than the ordinary concrete masonry units by facilitating the grout between the units, both vertically and horizontally. On the contrary, the thermal advantage is reducing the thermal bridges by using continuous insulation materials.

(2) The ultimate load and damage load of this new structural system are obviously improved, and the ductility is improved greatly with enhancement of energy dissipation capacity.

(3) In wall A2, the presence of the opening resulted in a reduction in shear strength of about $30 \%$, while the deflection was increased by approximately $24 \%$ when compared to the equivalent control wall (A1) without opening. Moreover, the opening in the wall resulted in a remarkable decrease in the stiffness and failure load and increased the deflection values.

(4) Through the analysis of the seismic activity of the wall, it can be seen that the new energy-saving block wall can meet the seismic shear calculation under the 8-degree rare earthquake and meet the antiseismic fortification target in the 8-degree area. Furthermore, "self-contained" system can greatly improve the seismic shear capacity of the wall.

(5) According to the test situation, the results showed that after the wall reached the limit state, the wall still had stiffness to withstand the displacement, which measured the ultimate bearing capacity equivalent to more than 8 or 9 degrees of earthquake shear and seismic forces, respectively; this meets with the basic principle of earthquakes.

(6) Compared with A1 and A2, it is found that the carrying capacity of "self-carrying" new energysaving block wall is better than that of the wall without frame and ring beam, and the improvement of seismic capacity is about $80 \%$, which is due to the fact that the ring beam itself involved in the shear; on the contrary, the structure of the column and ring beam formed a closed hoop, the common constraint of the top of the corner and displacement, making the role of horizontal force, resulting in vertical compressive stress, thereby improving the shear 
capacity of the member. It is proved that "selfcontained" structural column-ring beam system is completely feasible.

(7) Comparison of A2 and A3, indicates that the window (opening) has a greater impact on the wall capacity. So, it is very important to consider the reduction in the wall capacity due to presence of the opening inorder to strengthen the wall and to resist crack propagation.

\section{Conflicts of Interest}

The authors declare that they have no conflicts of interest.

\section{Acknowledgments}

This research was conducted with the financial support of the National “Twelfth Five-Year" Research Project in the National Science and Technology Pillar Program (Grant no. 2015BAL03B02).

\section{References}

[1] K. S. Ibrahim and G. T. Suter, "Ductility of concrete masonry shear walls subjected to cyclic loading," in Proceedings of the Eighth North American Masonry Conference, Austin, TX, USA, June 1999.

[2] M. T. Shedid, R. G. Drysdale, and W. W. El-Dakhakhni, "Behavior of fully grouted reinforced concrete masonry shear walls failing in flexure: experimental results," Journal of Structural Engineering, vol. 134, no. 11, pp. 1754-1767, 2008.

[3] M. T. Shedid, W. W. El-Dakhakhni, and R. G. Drysdale, "Seismic performance parameters for reinforced concreteblock shear wall construction," Journal of Performance of Constructed Facilities, vol. 24, no. 1, pp. 4-18, 2010.

[4] J. D. Sherman, Effects of Key Parameters on the Performance of Concrete Masonry Shear Walls under In-Plane Loading, Washington State University, Pullman, WA, USA, 2011.

[5] J. Brunner and P. Shing, "Shear strength of reinforced masonry walls," Masonry Society Journal, vol. 14, no. 1, pp. 65-76, 1996.

[6] S. Miller, W. El Dakhakhni, and R. Drysdale, "Experimental evaluation of the shear capacity of reinforced masonry shear walls," in Proceedings of 10th Canadian Masonry Symposium, Banff, Canada, June 2005.

[7] T. Paulay, "Earthquake-resisting shear walls-New Zealand design trends," ACI Journal Proceedings, vol. 77, no. 3, pp. 144-152, 1980.

[8] T. Paulay, M. Priestley, and A. Synge, "Ductility in earthquake resisting squat shear walls," ACI Journal Proceedings, vol. 79, no. 4, pp. 257-269, 1982.

[9] P. Shing, J. Noland, E. Klamerus, and H. Spaeh, "Inelastic behavior of concrete masonry shear walls," Journal of Structural Engineering, vol. 115, no. 9, pp. 2204-2225, 1989.

[10] P. Shing, M. Schuller, and V. Hoskere, "In-plane resistance of reinforced masonry shear walls," Journal of Structural Engineering, vol. 116, no. 3, pp. 619-640, 1990.

[11] K. Voon and J. Ingham, "Shear strength of concrete masonry walls," in Proceedings of 7 th Australasian Masonry Conference, Newcastle, Australia, July 2004.

[12] K. Voon and J. Ingham, "Experimental in-plane shear strength investigation of reinforced concrete masonry walls,"
Journal of Structural Engineering, vol. 132, no. 3, pp. 400-408, 2006.

[13] G. Fan, Z. Zhao, and G. Yang, "Cyclic response of reinforced concrete shear walls with continuous rectangular spiral stirrups," KSCE Journal of Civil Engineering, vol. 22, no. 5, pp. 1771-1781, 2017.

[14] A.-B. A. E. Mohamad and Z. Chen, "Experimental and numerical analysis of the compressive and shear behavior for a new type of self-insulating concrete masonry system," Applied Sciences, vol. 6, no. 9, p. 245, 2016.

[15] R. Marques and P. B. Lourenço, "Unreinforced and confined masonry buildings in seismic regions: validation of macroelement models and cost analysis," Engineering Structures, vol. 64, pp. 52-67, 2014.

[16] A. K. Marsono and S. Hatami, "Analysis of reinforced concrete shear walls with single band of octagonal openings," KSCE Journal of Civil Engineering, vol. 20, pp. 1887-1894, 2016.

[17] A.-B. A. E. Mohamad and Z. Chen, "Experimental studies on the behavior of a newly-developed type of self-insulating concrete masonry shear wall under in-plane cyclic loading," Applied Sciences, vol. 7, no. 5, p. 463, 2017.

[18] P. Asadi, R. Madandoust, and S. M. Zahrai, "Response modification factor due to ductility of screen-grid ICF wall system in high seismic risk zones," KSCE Journal of Civil Engineering, vol. 21, no. 1, pp. 258-264, 2017.

[19] A. Borri, G. Castori, and M. Corradi, "Shear behavior of unreinforced and reinforced masonry panels subjected to in situ diagonal compression tests," Construction and Building Materials, vol. 25, no. 12, pp. 4403-4414, 2011.

[20] J. Milosevic, M. Lopes, and A. S. Gago, "Testing and modeling the diagonal tension strength of rubble stone masonry panels," Engineering Structures, vol. 52, no. 9, pp. 581-591, 2013. 


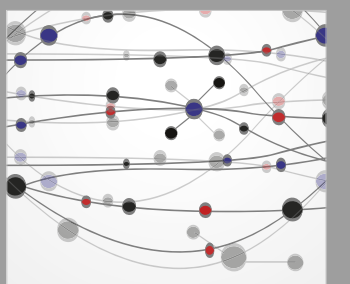

The Scientific World Journal
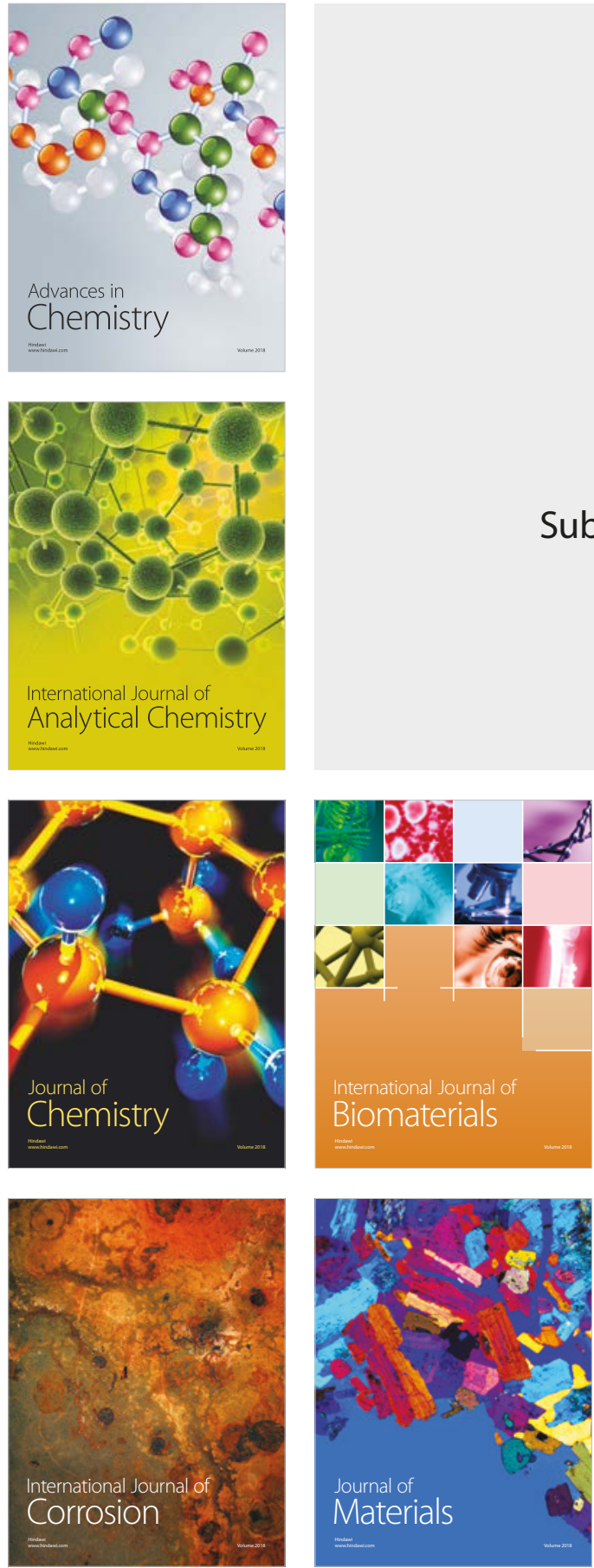

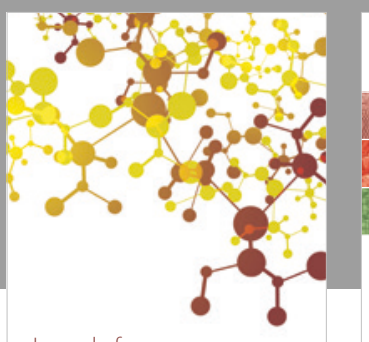

Journal of

Applied Chemistry
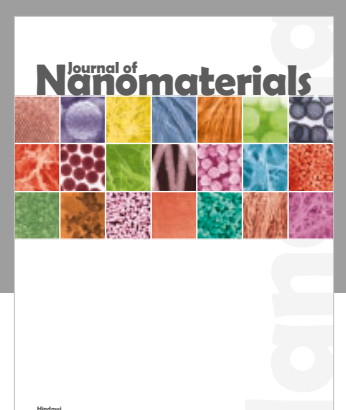

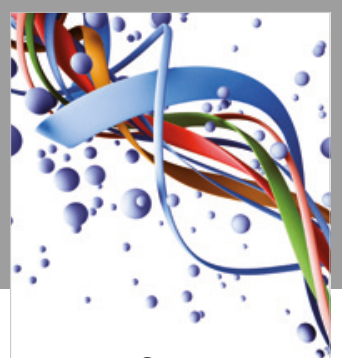

Scientifica

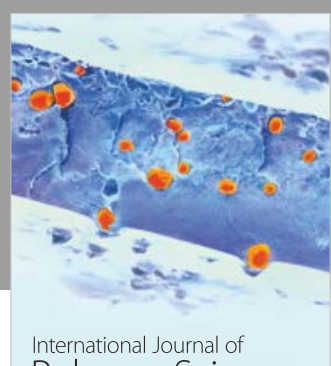

Polymer Science

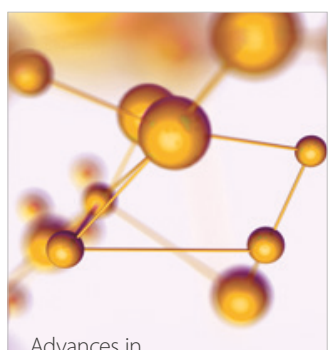

Physical Chemistry
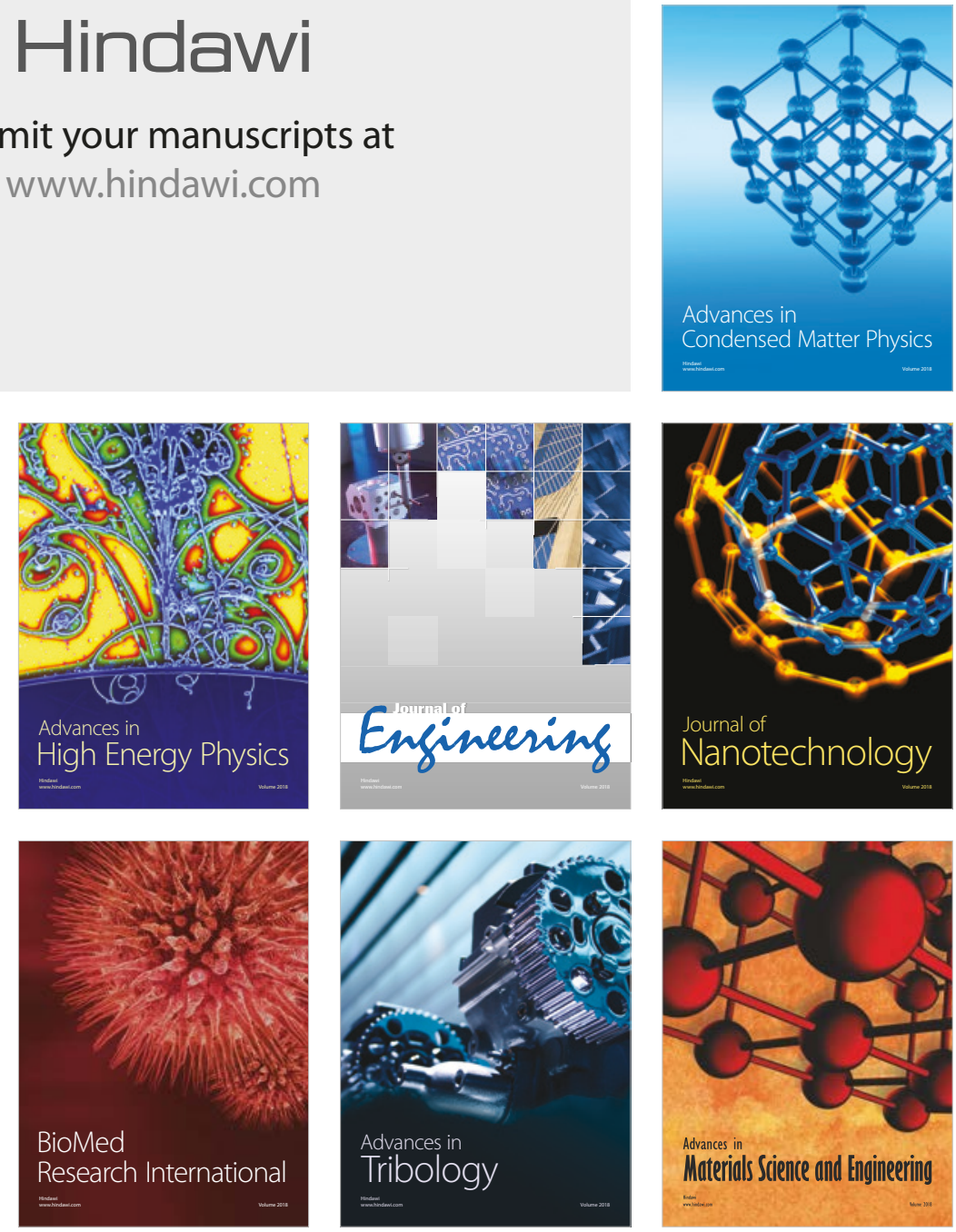